\title{
Lifetimes, transition probabilities, and level energies in Fe I
}

\author{
T. R. O'Brian, M. E. Wickliffe, and J. E. Lawler \\ University of Wisconsin-Madison, Madison, Wisconsin 53706
}

W. Whaling

California Institute of Technology, Pasadena, California 91125

\author{
J. W. Brault \\ National Solar Observatory, Tucson, Arizona 85726
}

Received October 1, 1990; accepted December 13, 1990

\begin{abstract}
We use time-resolved laser-induced fluorescence to measure the lifetime of $186 \mathrm{Fe}$ I levels with energies between 25900 and $60758 \mathrm{~cm}^{-1}$. Measured emission branching fractions for these levels yield transition probabilities for 1174 transitions in the range 225-2666 nm. We find another $640 \mathrm{Fe}$ I transition probabilities by interpolating level populations in the inductively coupled plasma spectral source. We demonstrate the reliability of the interpolation method by comparing our transition probabilities with absorption oscillator strengths measured by the Oxford group [Blackwell et al., Mon. Not. R. Astron. Soc. 201, 595-602 (1982)]. We derive precise Fe I level energies to support the automated method that is used to identify transitions in our spectra.
\end{abstract}

\section{INTRODUCTION}

We recently demonstrated with Mo I an automated method for extracting a large number of atomic transition probabilities of modest precision from Fourier-transform spectra. $^{1}$ In the present paper we apply this method to a more important and better-known atom, Fe I, for which accurate $g f$ values already exist against which we can test the results of our method. The method requires the radiative lifetime of many atomic levels - the more the betterwith excitation energies distributed over the maximum possible range; in Section 2 we report the measurement by laser fluorescence of the lifetime of $186 \mathrm{Fe}$ I levels between 25900 and $60758 \mathrm{~cm}^{-1}$.

In Section 3 we report the automated measurement of emission branching fractions for the decay of these levels and determine transition probabilities for the decay channels. In Section 4 we use the transition probabilities to investigate the population of excited Fe I levels in the inductively coupled plasma (ICP) source and show that one can interpolate between levels of known lifetimes, and hence of known populations, to find the population of new levels of unknown lifetime. Once the population of a level is known, the transition probability can be found for every measurable transition by which the level decays. The two methods combined yield 1814 transition probabilities. We publish in this paper only a sample of the stronger lines; as in the case of Mo I, those who need the complete results may obtain them on request in machinereadable form.

To establish the soundness of our population method and validate the uncertainty estimates that we assign, in Section 5 we compare Fe I transition probabilities measured by the lifetime and the population methods with the precise absorption oscillator strengths measured by Blackwell et $a l{ }^{2} \quad$ With the reliability of our results confirmed, we proceed to use our values to test the precision of two other collections of Fe I transition probabilities: the 1985 National Institute of Standards and Technology (NIST) compilation $^{3}$ (2092 lines) and the semiempirical values of Kurucz $^{4}\left(\sim 10^{6}\right.$ lines). To support the automated lineidentification process, in Section 6 we present improved Fe I level energies determined from our spectra, and we compare our level energies with those in the NIST Atomic Energy Levels ${ }^{5}$ (AEL).

\section{LEVEL LIFETIMES}

Radiative lifetimes for 186 levels of Fe I were measured with time-resolved laser-induced fluorescence on a slow Fe atomic beam. This approach has proved highly reliable for measurements on neutral and singly ionized atoms. ${ }^{6}$ Selective laser excitation eliminates the cascading problem that plagues beam-foil time-of-flight measurements. The beam environment eliminates errors that are due to radiation trapping and collisional quenching.

Figure 1 is a schematic of the experiment. The atomic or ionic beam source is based on a low-pressure large-bore hollow-cathode discharge. This versatile sputter source produces intense atomic or ionic beams of any metallic element. The hollow cathode is used to form uncollimated atomic or ionic beams by sealing one end of the cathode except for a 1.0-mm-diameter opening, flared outward at $45^{\circ}$. The hollow cathode and the scattering chamber are at ground potential. Ar, the sputtering gas, flows continuously into the hollow-cathode discharge. The scattering chamber is sealed from the hollow-cathode discharge, except for the nozzle, and is maintained at a much lower pressure than the discharge by a $10-\mathrm{cm}$ diffusion pump. The Ar pressure in the discharge is typically 0.4 Torr, while the scattering chamber pressure is $10^{-4}$ Torr. The hollow-cathode discharge is operated with dc currents of 

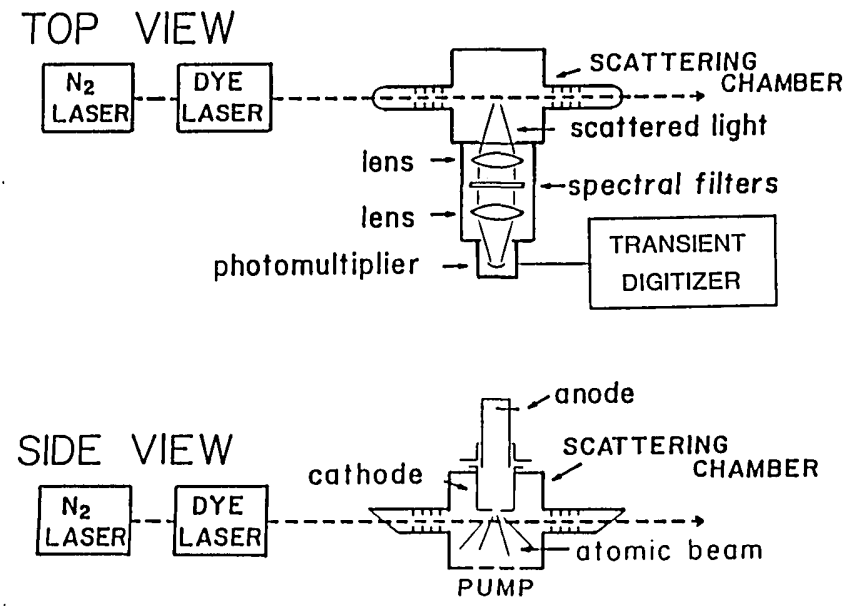

Fig. 1. Schematic diagram of the laser fluorescence apparatus.

20-200 $\mathrm{mA}$ and with 5- $\mu$ s pulses as large as $25 \mathrm{~A}$. When operated in a pulse mode the discharge current is maintained at $50 \mathrm{~mA}$ between pulses by the dc supply. A more detailed description of the source, including a drawing showing dimensions and materials, has been published. ${ }^{7}$

The atomic beam is crossed by a pulsed dye-laser beam $1.0 \mathrm{~cm}$ from the nozzle. The dye laser, pumped by a pulsed $\mathrm{N}_{2}$ laser, produces an optical pulse of 3-ns duration (FWHM) with a $0.2-\mathrm{cm}^{-1}$ bandwidth and a peak power of up to $40 \mathrm{~kW}$. Potassium dihydrogen phosphate (KDP) and $\beta$-barium borate (BBO) crystal frequency doublers extend the dye laser tuning range to $205 \mathrm{~nm}$ in the UV. The fluorescence is detected along an axis orthogonal to the atomic beam and laser beam. In order to minimize scattered light, several sets of light baffles are arranged along the laser-beam axis inside the Brewster windows that pass the laser beam into and out of the scattering chamber. Two independently tuned dye lasers were used to excite six of the high-lying even-parity levels by two-step laser excitation.

Two lenses composing an $f / 1$ system with unity magnification are used to collect the laser-induced fluorescence. The fluorescent light is approximately collimated between the two lenses. Interference filters or dye filters may be inserted between the lenses. Occasionally, branching ratios are favorable for observing fluorescence at a wavelength that is much different from the laser wavelength. Filters are used to block all scattered laser light and to isolate the laser-induced fluorescence whenever possible. Repopulation by radiative cascade from higher-lying levels is not a problem because of the highly selective laser excitation. Filters are used to block emission from lowerlying levels, which are populated by radiative cascade. High-lying even-parity levels are prone to produce cascade fluorescence from lower odd-parity levels.

The detection system is composed of a photomultiplier, a delay cable, and either a boxcar averager or a transient digitizer. The bias resistors of the 1P28A photomultiplier are bypassed with capacitors in order to ensure good linearity at large peak currents; small damping resistors are included to reduce ringing. All components are wired for low inductance and fast response. The 0,1-ns risetime delay cable is necessary for synchronization of electronic components when the boxcar averager is used. The window width of the PAR-163/162 boxcar averager is
75 ps. Most of the 6070 fluorescence decay curves for this study were logged with a Tektronix 7912AD transient digitizer, shown in Fig. 1, since its data collection rate is a hundred times that of the boxcar. The digitizer has an analog bandwidth of $0.5 \mathrm{GHz}$ and a sampling rate of $200 \mathrm{GHz}$. We often compared the two data-logging systems in order to test for small systematic errors. Measuring well-known $\mathrm{He} \mathrm{I}$ and $\mathrm{Be} \mathrm{I}$ lifetimes tests the accuracy of the experiment and confirms that lifetimes as short as $2 \mathrm{~ns}$ can be accurately measured. ${ }^{8}$ A trigger generator provides an adjustable delay between the current pulse to the hollow cathode and the laser pulse. Pulsing the atomic beam source has two advantages: It produces a much higher flux of atoms, especially in high metastable levels (while still maintaining low average discharge current), and it permits extensive studies of potential error in very long $(\sim 2-\mu \mathrm{s})$ lifetimes that arises from atoms' escaping from the observation region before radiating. ${ }^{9}$ Error due to atoms' escaping from the observation region before radiating is negligible in this $\mathrm{Fe} I$ experiment.

We routinely use more than one transition for laser excitation of a level. This redundancy provides a check that the chosen transitions have been correctly classified, are correctly identified in the experiment, and are unblended. Typically these independent measurements agree to a few percent. One of the most interesting discoveries during this investigation is that long-lived $\left(\geq 10^{-4} \mathrm{~s}\right)$ odd-parity levels have useful populations in the atomic beam. All but six of the lifetimes for high-lying even-parity levels were measured with single-step laser excitation. Twostep excitation, which was necessary for the six levels from the $e^{5} H$ and $e^{3} H$ terms, confirms the classification of lines connected to these levels, because the fluorescence from these levels is extinguished when either laser beam is interrupted.

The dynamic range of this experiment extends from 2-ns lifetimes, where it is limited by the electronic bandwidth of the detection apparatus, to $2-\mu$ s lifetimes, where it is limited by atoms' escaping from the observation region before radiating. Other possible systematic errors from radiation trapping, collisional quenching, or Zeeman quantum beats are unimportant. Tests for radiation trapping are routinely performed by variation of the atomic beam intensity. Many such tests on strong resonance transitions were performed, and radiation trapping of metal atom transitions was not detected. Collisional quenching is not a problem because of the low scattering chamber pressure $\left(10^{-4}\right.$ Torr of Ar). The absence of collisional quenching is confirmed by variation of the scattering chamber pressure when long lifetimes are measured. Zeeman quantum beats are avoided by measurement of short ( $<300-\mathrm{ns})$ lifetimes in zero magnetic field $(<20 \mathrm{mG})$ and long (>300-ns) lifetimes in a high $(30 \mathrm{G})$ field. We claim a total uncertainty that is the greater of $\pm 5 \%$ or $\pm 0.2 \mathrm{~ns}$ in our lifetime measurements. This uncertainty includes both systematic and random error. Our lifetime measurements and the transitions used for laser excitation are listed in Table 1.

A comparison of our measurements with those of previous investigations, especially laser-induced fluorescence measurements, provides convincing evidence that our total uncertainty is a realistic estimate of both systematic and random error. In Table 1 we list (on the line below our 
Table 1. Radiative Lifetime of Fe I Levels*

\begin{tabular}{|c|c|c|c|c|c|c|}
\hline Level & $\begin{array}{l}\text { Energy } \\
\left(\mathrm{cm}^{-1}\right)\end{array}$ & $\begin{array}{l}\text { Transitions } \\
(\mathrm{nm})\end{array}$ & $\begin{array}{l}z^{3} G_{5}^{\circ} \\
z^{5} G_{3}^{\circ}\end{array}$ & $\begin{array}{l}35379.204 \\
35611.621\end{array}$ & $\begin{array}{l}427.18 \\
433.70,441.51\end{array}$ & $\begin{array}{l}10.2 \\
10.2\end{array}$ \\
\hline $\mathrm{z}^{5} \mathrm{D}_{4}^{\circ}$ & \multicolumn{2}{|c|}{$89.0(4.8)^{\mathrm{a}}, 81.4(5.0)^{\mathrm{b}}, 78.5(2.0)^{\mathrm{c}}$} & $\begin{array}{l}\mathrm{z}^{3} \mathrm{G}_{4}^{\circ} \\
\mathrm{z}^{5} \mathrm{G}_{0}^{\circ}\end{array}$ & $\begin{array}{l}35767.560 \\
35856.397\end{array}$ & $\begin{array}{l}420.20,430.79 \\
436.79\end{array}$ & $\begin{array}{l}(6)^{\circ} \\
10.8 \\
9.9\end{array}$ \\
\hline$z^{5} D_{3}^{\circ}$ & 26140.177 & $\begin{array}{rr}388.63,532.80 & 81.1 \\
87.2(4.8)^{\mathrm{a}}, 83.5(5.0)^{\mathrm{b}}\end{array}$ & $\begin{array}{l}\mathrm{z}^{3} \mathrm{G}_{3}^{\mathrm{o}} \\
\mathrm{y}^{3} \mathrm{~F}_{4}^{\mathrm{o}}\end{array}$ & $\begin{array}{l}36079.368 \\
36686.172\end{array}$ & $\begin{array}{l}425.08,432.58 \\
404.58,414.39\end{array}$ & $\begin{array}{l}9.9 \\
11.7 \\
9.6\end{array}$ \\
\hline $\mathrm{z}^{5} \mathrm{D}_{2}^{\circ}$ & 26339.694 & $385.64,537.15 \quad 84.5$ & & & \multicolumn{2}{|c|}{$9.11(16)^{\mathrm{e}}$} \\
\hline $\mathrm{z}^{5} \mathrm{D}_{1}^{\circ}$ & 26479.376 & $\begin{array}{rr}94.7(5.3)^{\mathrm{a}}, 82.3(5.0)^{\mathrm{b}} \\
387.86,540.58 & 86.3 \\
91.2(5.0)^{\mathrm{a}}, 83.5(5.0)^{\mathrm{b}}\end{array}$ & $\begin{array}{l}\mathrm{y}^{5} \mathrm{P}_{3}^{\circ} \\
\mathrm{y}^{5} \mathrm{P}_{2}^{\mathrm{o}} \\
\mathrm{y}^{3} \mathrm{~F}_{3}^{\circ}\end{array}$ & $\begin{array}{l}36766.963 \\
37157.561 \\
37162.743\end{array}$ & $\begin{array}{l}403.26,520.23 \\
406.45,509.87 \\
406.36,413.21\end{array}$ & $\begin{array}{l}5.7 \\
6.0 \\
9.5\end{array}$ \\
\hline$z^{5} D_{0}^{\circ}$ & 26550.474 & $\begin{array}{rr}389.57,543.45 & 88.5 \\
88.6(5.0)^{\mathrm{a}}, 85.6(5.0)^{\mathrm{b}}\end{array}$ & $\mathrm{y}^{5} \mathrm{P}_{1}^{\circ}$ & 37409.549 & \multicolumn{2}{|c|}{$9.06(13)^{\mathrm{e}}$} \\
\hline$z^{5} F_{5}^{\circ}$ & 26874.546 & $\begin{array}{r}501.21,512.74 \\
62.4(4.2)^{\mathrm{b}}, 61.0(1.0)^{\mathrm{c}}\end{array}$ & $\mathrm{y}^{3} \mathrm{~F}_{2}^{\mathrm{o}}$ & 37521.157 & $\begin{array}{r}400.52,407.17 \\
9.0\end{array}$ & $6)^{9.6}$ \\
\hline $\mathrm{z}^{5} \mathrm{~F}_{4}^{\circ}$ & 27166.816 & $\begin{array}{r}505.16,514.29 \begin{array}{r}63.6 \\
63.7(4.0)^{\mathrm{b}}\end{array}\end{array}$ & $\begin{array}{l}\mathrm{y}^{3} \mathrm{D}_{3} \\
\mathrm{y}^{3} \mathrm{D}_{2}^{\mathrm{o}} \\
\mathrm{y}^{3} \mathrm{D}_{1}^{\mathrm{o}}\end{array}$ & $\begin{array}{l}38678.0348 \\
38695.731\end{array}$ & $\begin{array}{l}381.08,390.30 \\
382.78,388.85 \\
384.11\end{array}$ & $\begin{array}{l}7.1 \\
7.1 \\
7.2\end{array}$ \\
\hline $\mathrm{z}^{5} \mathrm{~F}_{3}^{\circ}$ & 27394.687 & $\begin{array}{r}499.41,508.33 \quad 66.3 \\
65.1(4.0)^{\mathrm{b}}\end{array}$ & $\begin{array}{l}\mathrm{x}^{5} \mathrm{D}_{4}^{\mathrm{o}} \\
\mathrm{x}^{5} \mathrm{D}_{3}^{\mathrm{o}}\end{array}$ & $\begin{array}{l}39625.799 \\
39969.848\end{array}$ & $\begin{array}{l}452.86 \\
449.46\end{array}$ & $\begin{array}{l}2.6 \\
2.6\end{array}$ \\
\hline $\mathrm{z}^{5} \mathrm{~F}_{2}^{\circ}$ & 27559.580 & $504.11,515.19 \quad 67.9$ & $\mathrm{y}^{7} \mathrm{P}_{2}^{\mathrm{o}}$ & 40052.018 & $255.26,444.28$ & 444 \\
\hline $\mathrm{z}^{5} \mathrm{~F}_{1}^{\circ}$ & 27666.344 & 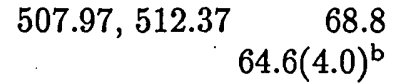 & $\begin{array}{l}\mathrm{y}^{7} \mathrm{P}_{3}^{\circ} \\
\mathrm{x}^{5} \mathrm{D}_{2}^{\circ}\end{array}$ & $\begin{array}{l}40207.090 \\
40231.332\end{array}$ & $\begin{array}{l}248.64,251.24 \\
448.23\end{array}$ & $\begin{array}{l}146 \\
2.6\end{array}$ \\
\hline$z^{3} D_{3}^{\circ}$ & 31322.610 & $319.17,532.85 \quad 254$ & $\mathrm{x}^{5} \mathrm{~F}_{5}^{\mathrm{O}}$ & 40257.307 & 248.33 & 2.0 \\
\hline $\mathrm{z}^{3} \mathrm{D}_{2}^{\circ}$ & 31686.349 & $319.70,534.10$ & $x^{5} D_{1}^{\circ}$ & 40404.513 & 444.77 & 2.6 \\
\hline$z^{3} D_{1}^{o}$ & 31937.323 & $322.91,527.04$ & $\mathrm{y}^{7} \mathrm{P}_{4}^{\circ}$ & 40421.938 & 247.32 & 309 \\
\hline $\mathrm{y}^{5} \mathrm{D}_{4}^{\circ}$ & 33095.937 & $382.04,388.71$ & $\begin{array}{l}\mathrm{X}^{0} \mathrm{D}_{0}^{\circ} \\
\mathrm{x}^{5} \mathrm{~F}^{\circ}\end{array}$ & $\begin{array}{l}40491.279 \\
40594.427\end{array}$ & $\begin{array}{l}443.06 \\
248.81\end{array}$ & 2.6 \\
\hline $\mathrm{y}^{5} \mathrm{D}_{3}^{0}$ & 33507.119 & $\begin{array}{lr}382.59,387.80 & 5.7 \\
& 6.1(5)^{\mathrm{d}}\end{array}$ & $\begin{array}{l}x+4 \\
x^{5} F_{3}^{o} \\
z^{5} S_{?}^{0}\end{array}$ & $\begin{array}{l}40842.149 \\
40894.986\end{array}$ & $\begin{array}{l}247.29 \\
248.74,428.24\end{array}$ & $\begin{array}{l}2.0 \\
2.0 \\
36.9\end{array}$ \\
\hline$y^{5} F_{5}^{\circ}$ & 33695.394 & $\begin{array}{r}7.9 \\
8.16(30)^{\mathrm{a}}\end{array}$ & $\begin{array}{l}\mathrm{x}^{5} \mathrm{~F}_{2}^{\circ} \\
\mathrm{x}^{5} \mathrm{~F}_{1}^{\circ}\end{array}$ & $\begin{array}{l}41018.046 \\
41130.594\end{array}$ & $\begin{array}{l}247.98 \\
248.42,248.98\end{array}$ & $\begin{array}{l}2.0 \\
2.0 \\
2.0\end{array}$ \\
\hline$y^{5} D_{2}^{\circ}$ & 33801.568 & $383.42,387.25 \quad 6.5$ & $\mathrm{x}^{5} \mathrm{P}_{3}^{\circ}$ & 42532.736 & $237.36,239.00$ & 46.6 \\
\hline $\mathrm{z}^{3} \mathrm{P}_{2}^{\mathrm{o}}$ & 33946.929 & $\begin{array}{rr}385.08,387.60 & 38.3 \\
37.0(2.2)^{\mathrm{b}}, 38.6(2.0)^{\mathrm{d}}\end{array}$ & $\begin{array}{l}\mathrm{y}^{5} \mathrm{G}_{6}^{\circ} \\
\mathrm{e}^{7} \mathrm{D}_{5}\end{array}$ & $\begin{array}{l}42784.350 \\
42815.851\end{array}$ & $\begin{array}{l}278.81 \\
426.05\end{array}$ & $\begin{array}{l}16.9 \\
8.3\end{array}$ \\
\hline$y^{5} D_{1}^{\circ}$ & 34017.099 & $\begin{array}{lr}384.04,386.55 & 5.8 \\
& 6.1(2)^{\mathrm{d}}\end{array}$ & $\begin{array}{l}\mathrm{x}^{5} \mathrm{P}_{2}^{\mathrm{o}} \\
\mathrm{y}^{5} \mathrm{G}_{5}^{\mathrm{o}}\end{array}$ & $\begin{array}{l}42859.773 \\
42911.911\end{array}$ & $\begin{array}{l}237.14,238.18 \\
277.82,281.33\end{array}$ & $\begin{array}{l}30.4 \\
23.1\end{array}$ \\
\hline $\mathrm{y}^{5} \mathrm{~F}_{4}^{\circ}$ & 34039.512 & $\begin{array}{r}453.12,465.45 \quad 7.7 \\
8.29(30)^{\mathrm{a}}\end{array}$ & $\begin{array}{l}\mathrm{z}^{5} \mathrm{H}_{5}^{\circ} \\
\mathrm{y}^{5} \mathrm{G}_{4}^{\circ} \\
\mathrm{x}^{5} \mathrm{P}_{1}^{\mathrm{o}}\end{array}$ & $\begin{array}{l}42991.693 \\
43022.979 \\
43079.019\end{array}$ & $\begin{array}{l}280.70 \\
280.45,283.24 \\
237.45\end{array}$ & $\begin{array}{l}72.1 \\
28.6 \\
93.0\end{array}$ \\
\hline $\mathrm{y}^{5} \mathrm{D}_{0}^{\circ}$ & 34121.597 & $\begin{array}{r}5.8 \\
5.9(2)^{\mathrm{d}}\end{array}$ & $\begin{array}{l}\mathrm{x}^{5} \mathrm{H}_{1}^{\circ} \\
\mathrm{z}^{5} \mathrm{H}_{4}^{\circ} \\
\mathrm{y}^{5} \mathrm{G}_{3}^{\circ}\end{array}$ & $\begin{array}{l}43108.913 \\
43137.483\end{array}$ & $\begin{array}{l}279.78,282.56 \\
282.33\end{array}$ & $\begin{array}{l}50.0 \\
55.2 \\
20.5\end{array}$ \\
\hline $\mathrm{y}^{5} \mathrm{~F}_{3}^{\circ}$ & 34328.748 & $\begin{array}{rr}459.27,468.03 & 7.7 \\
7.92(25)^{\mathrm{a}}\end{array}$ & $\begin{array}{l}\mathrm{e}^{7} \mathrm{D}_{4} \\
\mathrm{y}^{5} \mathrm{G}_{2}^{\circ}\end{array}$ & $\begin{array}{l}43163.321 \\
43210.020\end{array}$ & $\begin{array}{l}423.59,427.12 \\
281.75,283.81\end{array}$ & $\begin{array}{l}8.5 \\
20.8\end{array}$ \\
\hline $\mathrm{z}^{3} \mathrm{P}_{1}^{\circ}$ & 34362.869 & $\begin{array}{c}379.01,381.45 \\
94.1(5.5)^{\mathrm{b}}, 112(11)^{\mathrm{d}}\end{array}$ & $\begin{array}{l}\mathrm{z}^{5} \mathrm{H}_{3}^{2} \\
\mathrm{e}^{7} \mathrm{D}_{3}\end{array}$ & $\begin{array}{l}43325.960 \\
43434.624\end{array}$ & $\begin{array}{l}282.88 \\
418.78,425.01\end{array}$ & $\begin{array}{l}391 \\
8.4\end{array}$ \\
\hline $\mathrm{y}^{5} \mathrm{~F}_{2}^{\circ}$ & 34547.206 & 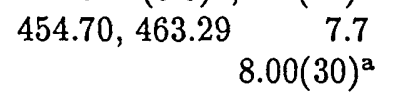 & $\begin{array}{l}w^{5} D_{4}^{\circ} \\
e^{7} D_{2}\end{array}$ & $\begin{array}{l}43499.503 \\
43633.529\end{array}$ & $\begin{array}{l}273.36,385.26 \\
418.70,423.36\end{array}$ & $\begin{array}{l}7.4 \\
8.4\end{array}$ \\
\hline $\mathrm{z}^{3} \mathrm{P}_{0}^{\circ}$ & 34555.592 & $\begin{array}{c}296.94,378.67 \quad 112 \\
108.0(7.0)^{\mathrm{b}}, 111.5(5.0)^{\mathrm{d}}\end{array}$ & $\begin{array}{l}e^{7} D_{1} \\
w^{5} D_{3}^{o} \\
5\end{array}$ & $\begin{array}{l}43763.977 \\
43922.665 \\
44022.521\end{array}$ & $\begin{array}{l}419.14,421.03 \\
273.55,381.63 \\
229.25,272.80\end{array}$ & $\begin{array}{l}8.4 \\
8.5 \\
95.9\end{array}$ \\
\hline $\mathrm{y}^{5} \mathrm{~F}_{1}^{\circ}$ & 34692.143 & $\begin{array}{rr}460.20 & 7.8 \\
& 7.86(25)^{\mathrm{a}}\end{array}$ & $\begin{array}{l}{ }^{5} \mathrm{D}_{4}^{\circ} \\
{ }^{5} \mathrm{D}_{3}^{\circ} \\
\mathrm{w}^{5} \mathrm{D}_{2}^{\circ}\end{array}$ & $\begin{array}{l}44022.521 \\
44166.200 \\
44183.622\end{array}$ & $\begin{array}{l}229.25,272.80 \\
230.01,274.36 \\
274.23,316.14\end{array}$ & $\begin{array}{l}95.9 \\
68.3 \\
8.9\end{array}$ \\
\hline$z^{5} G_{5}^{\circ}$ & 34782.417 & $\begin{array}{l}11.6 \\
11.7(7)^{\mathrm{b}}\end{array}$ & $\begin{array}{l}5 . \mathrm{F}_{5}^{\mathrm{O}} \\
{ }^{5} \mathrm{~F}_{2}^{\mathrm{o}}\end{array}$ & $\begin{array}{l}44243.682 \\
44285.451\end{array}$ & $\begin{array}{l}225.95,267.91 \\
229.38,230.36\end{array}$ & $\begin{array}{l}39.0 \\
54.0\end{array}$ \\
\hline$z^{5} G_{4}^{o}$ & 35257.321 & 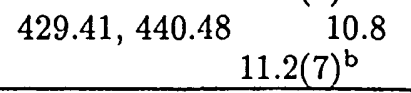 & ${ }^{5} \mathrm{~F}_{1}^{\mathrm{O}}$ & 44378.338 & $229.87,230.34$ & 41.7 \\
\hline
\end{tabular}


Table 1. Continued

\begin{tabular}{|c|c|c|c|c|c|c|c|}
\hline Level & $\begin{array}{l}\text { Energy } \\
\left(\mathrm{cm}^{-1}\right)\end{array}$ & $\begin{array}{c}\text { Transitions } \\
\text { (nm) }\end{array}$ & $\begin{array}{c}\tau \\
(\mathrm{ns}) \\
\end{array}$ & $\begin{array}{l}f^{7} D_{1} \\
e^{7} F_{3}\end{array}$ & $\begin{array}{l}51048.100 \\
51148.857\end{array}$ & $\begin{array}{l}321.08 \\
316.50,318.46,\end{array}$ & $\begin{array}{l}7.0 \\
8.3\end{array}$ \\
\hline $\mathrm{w}^{5} \mathrm{D}_{1}^{\circ}$ & 44411.153 & $274.45,275.73$ & 10.5 & & & 320.05 & \\
\hline & 44415.069 & $227.21,269.91$ & 41.2 & $e^{5} S_{2}$ & 51148.905 & 321.15 & 9.6 \\
\hline$w^{5} D_{0}^{4}$ & 44458.930 & $229.44,275.37$ & 11.5 & $e^{7} F_{4}$ & 51192.269 & 318.02 & 6.5 \\
\hline & 44511.807 & $226.71,271.78$ & 13.6 & $\mathrm{e}^{7} \mathrm{~F}_{1}$ & 51207.993 & 320.54 & 5.9 \\
\hline & 44551.333 & $227.99,268.92$ & 41.6 & $e^{5} G_{3}$ & 51219.012 & $315.80,319.33$ & 9.5 \\
\hline${ }^{5} \mathrm{D}$ & 44664.074 & $228.37,270.66$ & 31.7 & $e^{7} G_{5}$ & 51228.548 & 315.70 & 7.8 \\
\hline${ }^{5} \mathrm{D}$ & 44760.741 & $226.91,271.84$ & 21.4 & $e^{7} F_{2}$ & 51331.050 & 318.19 & 7.4 \\
\hline $5 D_{0}^{c}$ & 44826.880 & $227.52,272.61$ & 16.3 & $e^{7} G_{4}$ & 51334.905 & 316.59 & 7.5 \\
\hline$x^{3} D_{3}^{\circ}$ & 45220.674 & $223.12,264.16$ & 23.0 & $e^{5} G_{2}$ & 51370.141 & $316.23,318.88$ & 10.3 \\
\hline $\begin{array}{l}x+3 \\
x^{3} D_{?}^{0}\end{array}$ & 45281.828 & $225.19,388.55$ & 21.3 & $e^{7} G_{3}$ & 51460.514 & $315.33,316.89$ & 6.7 \\
\hline $\mathrm{y}^{3} \mathrm{G}_{5}^{\mathrm{o}}$ & 45294.841 & $260.57,385.92$ & 55.7 & $\mathrm{f}^{5} \mathrm{~F}_{4}$ & 51461.669 & 315.32 & 12.7 \\
\hline$y^{3} G_{4}^{0}$ & 45428.397 & $387.38,389.90$ & 64.0 & $e^{7} G_{2}$ & 51539.718 & 317.17 & 6.7 \\
\hline$x^{3} I$ & 45551.760 & $306.82,384.52$ & 19.8 & $\mathrm{e}^{7} \mathrm{~S}_{3}$ & 51570.094 & $314.25,315.79$ & 7.3 \\
\hline$y^{3}$ & 45562.970 & $266.04,306.71$ & 67.2 & $\mathrm{f}^{5} \mathrm{~F}_{3}$ & 51604.100 & 315.45 & 14.8 \\
\hline & 45608.358 & 258.45 & 31.4 & $\mathrm{w}^{3} \mathrm{H}_{6}^{\circ}$ & 52431.438 & $302.56,379.75$ & 8.9 \\
\hline$x^{5}$ & 45726.126 & $257.67,260.68$ & 28.1 & $\mathrm{y}^{3} \mathrm{I}_{6}^{\circ}$ & 52513.552 & 303.93 & 11.2 \\
\hline$x^{5}$ & 45833.219 & 262.35 & 26.8 & $\mathrm{w}^{3} \mathrm{H}_{5}^{\circ}$ & 52613.083 & $303.01,380.67$ & 9.1 \\
\hline$x^{5}$ & 45913.498 & $261.80,263.58$ & 26.4 & $\mathrm{y}^{3} \mathrm{I}_{7}^{\circ}$ & 52654.983 & 300.53 & 10.2 \\
\hline$x^{5} G_{2}^{o}$ & 45964.953 & $263.22,264.40$ & 26.8 & $\mathrm{w}^{3} \mathrm{H}_{4}^{\circ}$ & 52768.736 & $303.12,382.43$ & 9.3 \\
\hline$z^{3} I$ & 45978.002 & 376.01 & 191 & $\mathrm{y}^{3} \mathrm{I}_{5}^{\circ}$ & 52898.990 & 300.41 & 10.7 \\
\hline $\mid \begin{array}{l}2 \\
z^{3} I\end{array}$ & 46026.965 & 378.60 & 200 & \multirow{2}{*}{\multicolumn{4}{|c|}{$\begin{array}{r}538.34+438.36 \quad 12.8 \\
12.8(8)^{\mathrm{b}}\end{array}$}} \\
\hline$z^{3} I$ & 46135.812 & 379.43 & 211 & & & & \\
\hline $\mathrm{z}^{3} \mathrm{H}_{6}^{\circ}$ & 46982.315 & $249.59,395.67$ & 43.3 & $g^{7} D_{5}$ & 53800.856 & $290.19,320.93$ & 22.7 \\
\hline $\mathrm{z}^{3} \mathrm{H}^{6}$ & 47008.366 & $252.25,399.74$ & 35.9 & $\mathrm{e}^{3} \mathrm{H}_{6}$ & 53840.614 & $541.52+427.18$ & 12.8 \\
\hline $3 \pi$ & 47106.479 & $251.63,284.57,402.19$ & 36.5 & $e^{5} \mathrm{H}_{5}$ & 53874.251 & $537.00+440.48$ & 12.9 \\
\hline $\mathrm{w}^{5} \mathrm{G}_{6}^{\circ}$ & 47363.371 & 389.79 & 60.0 & & & \multicolumn{2}{|c|}{$13.4(9)^{\mathrm{b}}$} \\
\hline $5 \mathrm{CO}^{\circ}$ & 47420.224 & $246.89,249.65$ & 20.2 & $t^{3} G_{5}^{\circ}$ & 53983.294 & 309.82 & 12.0 \\
\hline$w$ & 47590.042 & $248.60,250.79$ & 35.5 & $g^{7} D_{4}$ & 54124.735 & $289.25,290.89$ & 24.3 \\
\hline$w^{5} G_{3}^{0}$ & 47693.236 & $251.77,389.08$ & 41.0 & $\mathrm{e}^{5} \mathrm{H}_{4}$ & 54237.156 & $536.75+441.51$ & 12.9 \\
\hline $\mathrm{x}^{3} \mathrm{G}_{4}^{\mathrm{O}}$ & 47812.114 & $244.52,283.59$ & 44.8 & $\mathrm{t}^{3} \mathrm{G}_{4}^{0}$ & 54237.409 & $288.80,307.40$ & 10.9 \\
\hline${ }^{5} C^{4} \mathrm{o}$ & 47831.149 & $251.96,390.79$ & 34.2 & $\mathrm{e}^{3} \mathrm{H}_{5}^{4}$ & 54266.706 & $540.42+430.79$ & 13.0 \\
\hline$x$ & 47834.215 & $249.26,250.88$ & 102 & $\mathrm{e}^{3} \mathrm{H}_{4}$ & 54555.413 & $541.09+432.58$ & 13.7 \\
\hline$x^{3} G_{5}^{0}$ & 47834.547 & $244.39,247.10$ & 43.6 & $t^{3} G_{3}^{\circ}$ & 54600.345 & $306.65,309.02$ & 10.1 \\
\hline 540 & 48231.275 & $242.04,377.03$ & 175 & $g^{7} D_{2}$ & 54611.711 & $286.82,318.18$ & 22.8 \\
\hline${ }^{5} \mathrm{H}$ & 48361.875 & $279.24,379.22$ & 139 & $\mathrm{~g}^{7} \mathrm{D}_{1}$ & 54747.608 & $286.98,317.34$ & 23.0 \\
\hline${ }^{5} \mathrm{H}$ & 48475.680 & $281.55,364.37,381.19$ & 130 & ${ }^{3} \mathrm{H}_{4}^{\circ}$ & 55446.004 & $280.36,301.15$ & 17.0 \\
\hline $\mathrm{y}^{3} \mathrm{H}_{6}^{\circ}$ & 49434.159 & 389.75 & 11.5 & ${ }^{3} \mathrm{H}_{6}^{\mathrm{q}}$ & 55489.734 & $276.93,296.00$ & 11.1 \\
\hline $13 \cap 0$ & 49460.896 & $266.70,389.34$ & 11.4 & ${ }^{3} \mathrm{H}_{5}^{\circ}$ & 55525.555 & $278.43,295.69$ & 9.0 \\
\hline 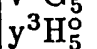 & 49604.422 & $265.68,387.17$ & 11.6 & $\mathrm{u}^{3} \mathrm{H}_{6}^{\circ}$ & 56333.955 & $270.60,288.78$ & 19.8 \\
\hline$v^{3} G_{4}^{\circ}$ & 49627.878 & $269.70,391.91$ & 11.3 & $\mathrm{u}^{3} \mathrm{H}_{5}^{\circ}$ & 56382.656 & $271.94,290.75$ & 12.6 \\
\hline $\mathrm{y}^{3} \mathrm{H}_{4}^{\circ}$ & 49726.985 & $268.98,390.39$ & 11.3 & $\mathrm{u}^{3} \mathrm{H}_{4}^{\circ}$ & 56423.276 & $271.64,272.88$ & 10.4 \\
\hline & 49850.584 & $271.05,391.86$ & 11.6 & $\mathrm{u}^{3} \mathrm{~F}_{4}^{0}$ & 56592.695 & $271.63,278.07,304.7$ & 9.9 \\
\hline$e^{7} 1$ & 50342.127 & 322.58 & 5.6 & $\mathrm{u}^{3} \mathrm{~F}_{3}^{\mathrm{O}}$ & 56783.316 & $278.40,306.05$ & 11.4 \\
\hline$f^{7} I$ & 50377.905 & 324.42 & 5.7 & $x^{3} I_{7}^{0}$ & 57027.505 & 265.62 & 17.2 \\
\hline & 50522.940 & 320.71 & 13.0 & $\mathrm{x}^{3} \mathrm{I}_{6}^{\circ}$ & 57070.165 & 266.95 & 17.4 \\
\hline & & \multicolumn{2}{|c|}{$13.0(8)^{b}, 13.0(7)^{\mathrm{f}}$} & & 57104.205 & $307.32,328.03$ & 17.2 \\
\hline$G_{5}$ & 50703.865 & \multirow{2}{*}{\multicolumn{2}{|c|}{$318.86,321.02 \quad 11.5$}} & $t^{3} F_{4}^{o}$ & 57550.005 & $270.86,278.98$ & 9.2 \\
\hline & & & & $t^{3} F_{3}^{0}$ & 57641.005 & $254.62,270.19$ & 7.9 \\
\hline$f^{7} D_{4}$ & 50807.993 & 321.96 & 6.2 & $t^{3} F_{2}^{0}$ & 57708.742 & $271.41,272.62$ & 8.9 \\
\hline & 50833.432 & 317.54 & 6.7 & & 58792.247 & 253.72 & 2.7 \\
\hline $\mathrm{f}^{7} \mathrm{D}_{3}$ & 50861.816 & 321.40 & 7.4 & ${ }^{3} I_{6}^{\circ}$ & 58946.730 & 254.21 & $2.0^{\circ}$ \\
\hline$e^{7} G_{6}$ & 50967.826 & 316.20 & 6.5 & ${ }^{3} \mathrm{I}_{5}^{\circ}$ & 59085.825 & 254.39 & 2.0 \\
\hline & 50979.574 & 318.21 & 12.8 & $\mathrm{t}^{3} \mathrm{H}_{6}^{\circ}$ & 60365.631 & 243.97 & 2.1 \\
\hline & & 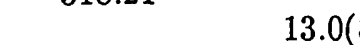 & $8)^{b}$ & $\mathrm{t}^{3} \mathrm{H}_{5}^{\circ}$ & 60549.110 & 244.26 & 2.1 \\
\hline$f^{7} D_{2}$ & 50998.641 & 321.59 & 7.5 & $\mathrm{t}^{3} \mathrm{H}_{4}^{\circ}$ & 60757.600 & $244.01,249.20$ & 2.1 \\
\hline
\end{tabular}

*The uncertainty of our value in the last column is the larger of $\pm 5 \%$ or $\pm 0.2 \mathrm{~ns}$. Other values measured by laser fluorescence are listed below our result. The uncertainty in the last digit(s) of the other values appears in parentheses.

${ }^{a}$ Ref. $10,{ }^{b}$ Ref. $11,{ }^{c}$ Ref. $12,{ }^{d}$ Ref. 13, ${ }^{e}$ Ref. $14,{ }^{f}$ Ref. 15. 
value) lifetimes for 31 levels that have been measured by other groups ${ }^{10-15}$ using laser-induced fluorescence. The uncertainty in the last digit(s) of each entry is enclosed in parentheses following the entry. Our measurements of these level lifetimes agree within the combined error estimates in essentially every case.

\section{TRANSITION PROBABILITIES FROM LEVEL LIFETIMES}

Given the radiative lifetime $\tau_{u}$ of excited level $u$, the transition probability $A_{u l}$ for the transition from level $u$ to level $l$ is given by

$$
A_{u l}=\mathrm{BF}_{u l} / \tau_{u}
$$

where $\mathrm{BF}_{u l}$ is the emission branching fraction for the transition. We find $\mathrm{BF}_{u l}$ from the line intensities $\mathrm{BF}_{u l}=$ $I_{u l} / \Sigma_{l^{\prime}} I_{u l^{\prime}}$, where $I$ is the intensity (in photons per second) of a line after correction for spectrometer response and the sum is taken over all lower levels $l^{\prime}$ to which the upper level $u$ decays. The spectrophotometry of the line intensities is standard and has been described in detail in Ref. 1; only a summary of the significant parameters will be presented here.

Fourteen spectra, all recorded on the 1-m Fouriertransform spectrometer ${ }^{16}$ (FTS) at the National Solar Observatory, Kitt Peak, were measured with the automated DECOMP program that fits a Voigt profile to an observed line to find the line-center wave number and the integrated line area. Nine of the spectra were recorded with a hollow-cathode source ${ }^{17}$ operating at a few Torr of pressure of $\mathrm{Ar}, \mathrm{Ar}+\mathrm{Ne}$, or $\mathrm{Ar}+\mathrm{He}$ and at source power levels between 17 and $140 \mathrm{~W} / \mathrm{cm}^{3}$ of cathode cavity. Si diodes (250-1000 nm), InSb diodes (1000-5000 nm), and solar-blind photoelectric detectors $(225-300 \mathrm{~nm})$ were used for different spectral ranges.

The response of the spectrometer system was determined internally for each spectrum from the observed intensity of Ar lines whose true intensity ratios are known, as described in Ref. 1. We extended this branching-ratio method for calibrating spectrometer response into the IR in this experiment by using $\mathrm{He}$ line pairs that span the range 400-3300 $\mathrm{nm}$ to calibrate a broad range spectrum in which an InSb IR detector was installed on one of the FTS exit channels and a UV Si detector on the other. The use of the two exit channels of the FTS as independent spectrometers was described by Wiese et $a l .{ }^{18}$ The He transition strengths were calculated most recently by Fernley et $a l .,{ }^{19}$ and we used their values for this calibration.

Five spectra measured for this experiment were excited in an inductively coupled Ar plasma source that contained a trace of $\mathrm{Fe}(\mathrm{CO})_{5}$ and operated at $27 \mathrm{MHz}, 1 \mathrm{~kW}$, and 600 Torr of Ar. The distinctive features of the ICP spectrum were discussed in Ref. 1, and we mention only two that we exploit in this work: the broad linewidth (from Doppler broadening at $\sim 7000 \mathrm{~K}$ ) and the distribution of excited-level populations, which we discuss in Section 5. Emission spectrophotometry is always threatened by selfabsorption, a threat that increases as the linewidth narrows. We found that the extremely broad lines of the ICP source are much less prone to self-absorption than are those of the hollow-cathode source, and we measured the intensity of strong decay channels on the ICP spectra whenever possible.

The population of excited levels in the ICP falls off exponentially as the excitation increases, so that the ICP spectrum is most useful for lines from lower levels, which are, fortunately, those most likely to be self-absorbed. To guard against self-absorption of lines from higher levels that could be measured only on the hollow-cathode spectrum, we used the standard technique of decreasing the source power until line-intensity ratios held constant. We also used an attractive feature of the DECOMP program: After fitting the parameers of a Voigt profile to the observed line, DECOMP displays the residual difference between the observed line and the Voigt profile. Selfabsorption produces a characteristic symmetrical doublehumped residual that is easily recognized long before any sign of self-absorption is apparent in the experimental line shape.

Although the ICP is an Ar plasma, Ar lines are not prominent in our ICP spectra and cannot be used to calibrate the response. Instead we used well-known $\mathrm{Fe}$ branching ratios to establish reference points on the response curve and filled in between these points with the observed response to a commercial W-ribbon radiance standard.

Line-intensity ratios on the 14 measured spectra were intercompared, averaged, and combined so we could find the branching fractions for levels of measured lifetimes. We believe that we have included in the sum in Eq. (1) all significant transitions, because we chose for lifetime measurement only levels that are known or expected to decay within the $4000-45000 \mathrm{~cm}^{-1}$ range of our spectra. Our expectation derives from the semiempirical branching ratios computed by Kurucz ${ }^{4}$; in Section 5 we test his theoretical predictions against experiment and find their accuracy to be adequate for this purpose.

With the radiative lifetimes of Table 1, our experimental branching fractions yield 1174 transition probabilities. A sample of these results are shown in Table 2. The fractional uncertainty $\pm \Delta A / A$ in the transition probability shown in parentheses for each line includes contributions from the uncertainty in the lifetime (5-10\%), from the uncertainty $\Delta I$ in each line intensity included in the braching fraction, and from the uncertainty in the response function. For $\Delta I$ we use the empirical function of the signal-to-noise ratio deduced by Faires et al. ${ }^{20}$ The response function $R(\lambda)$ contributes to the uncertainty $\Delta \mathrm{BF}$ (and hence to $\Delta A$ ) in a complex way because it is only the relative response $\left[R\left(\lambda_{l}\right) / R\left(\lambda_{l^{\prime}}\right)\right]$ that is significant. The uncertainty in this ratio increases as the separation $\lambda_{l}-\lambda_{l^{\prime}}$ increases. We have assumed a linear dependence on line separation:

$$
\Delta\left[R\left(\lambda_{l}\right) / R\left(\lambda_{l^{\prime}}\right)\right]=10^{-5}\left(\lambda_{l}-\lambda_{l^{\prime}}\right)\left[R\left(\lambda_{l}\right) / R\left(\lambda_{l^{\prime}}\right)\right],
$$

with a proportionality constant of $0.001 \%$ per wave number, based on our experience with the branching-ratio method for calibrating spectrometer response. With this assumption the response function makes by far the largest contribution to the $\Delta A$ for lines that are far removed from the strongest decay channels. We test the reliability of our uncertainty estimates in Section 5. 
Table 2. Transition Probability for 478 Strong Lines in Fe I* $^{*}$

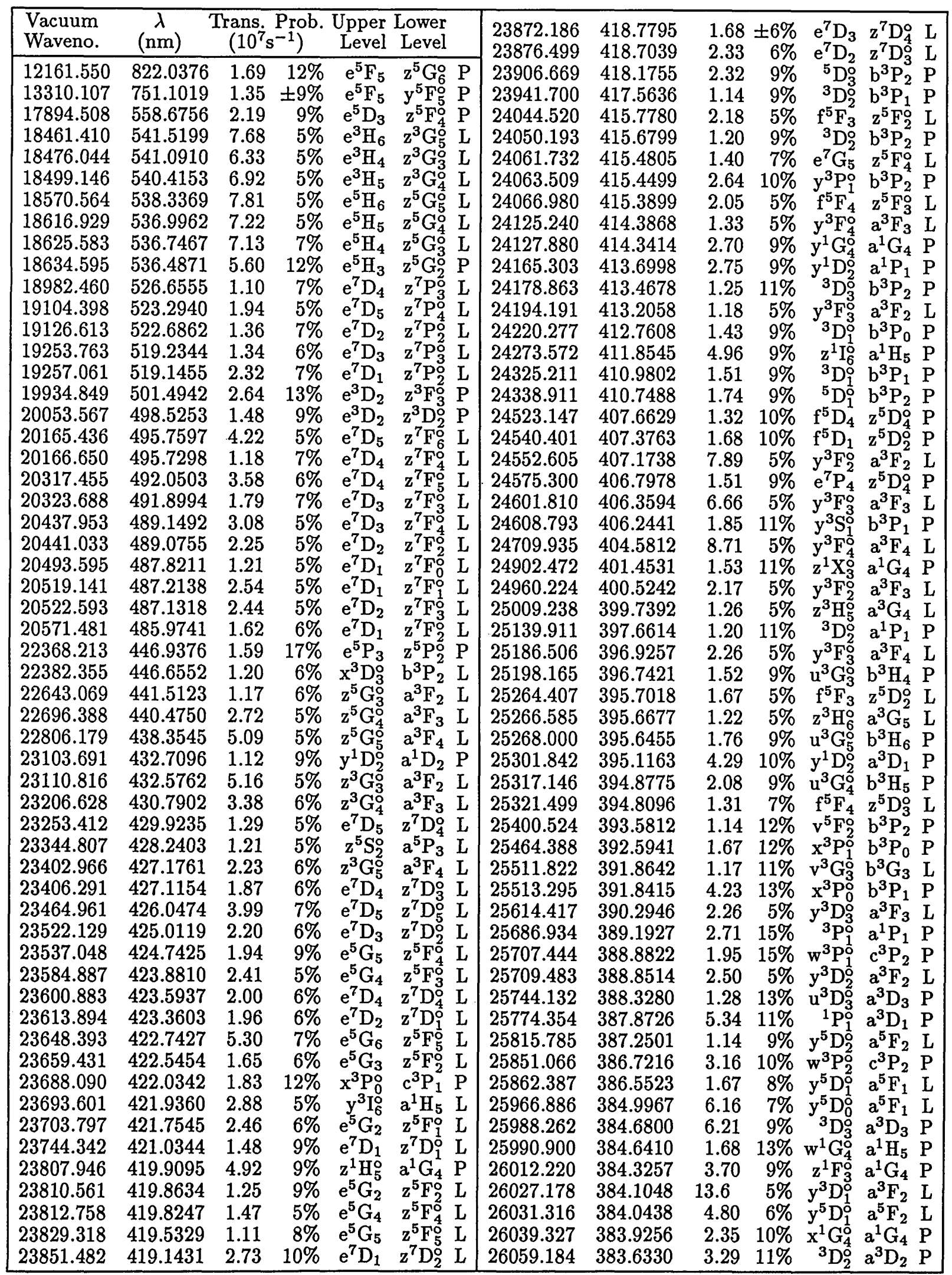


Table 2. Continued

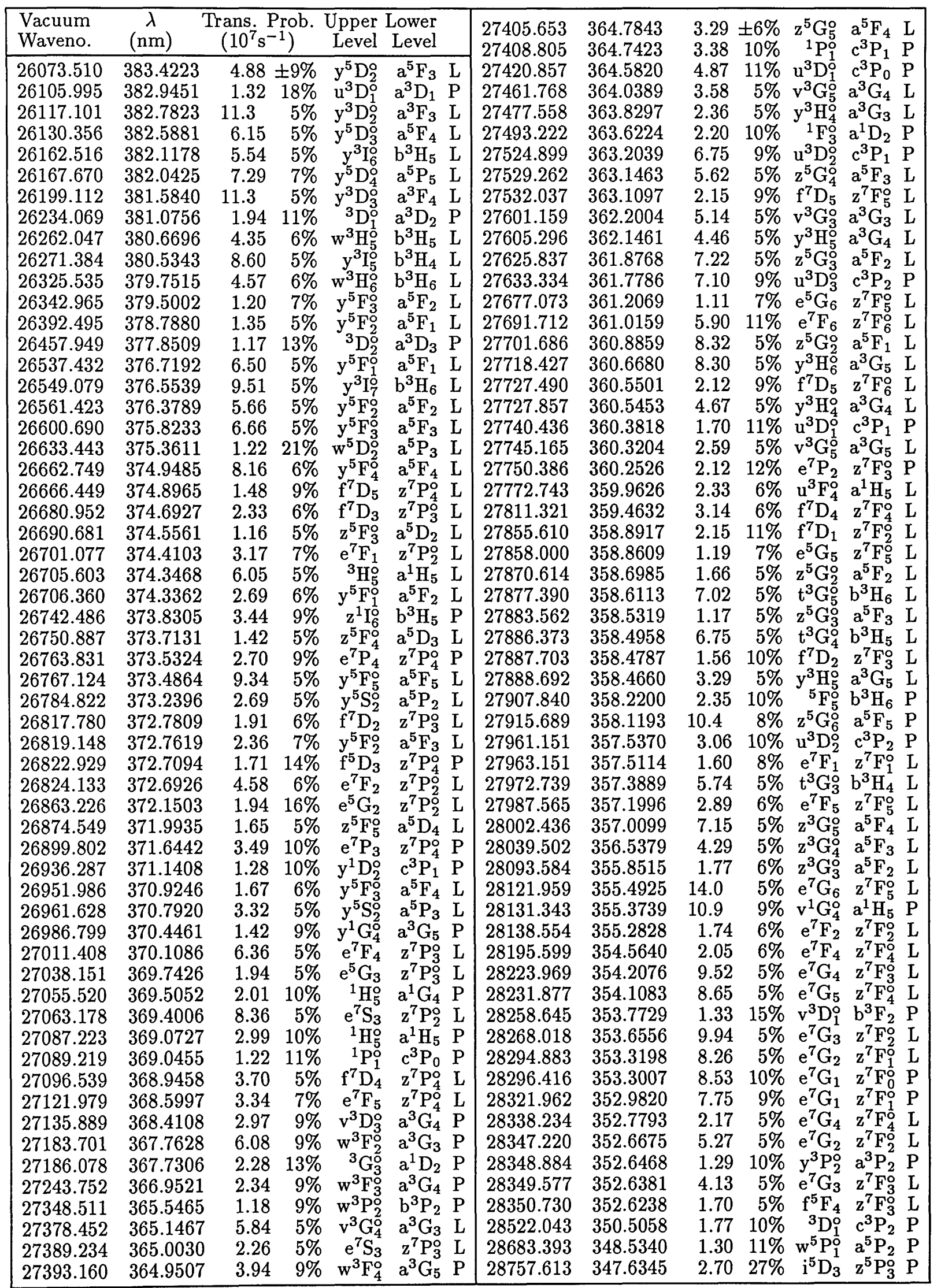


Table 2. Continued

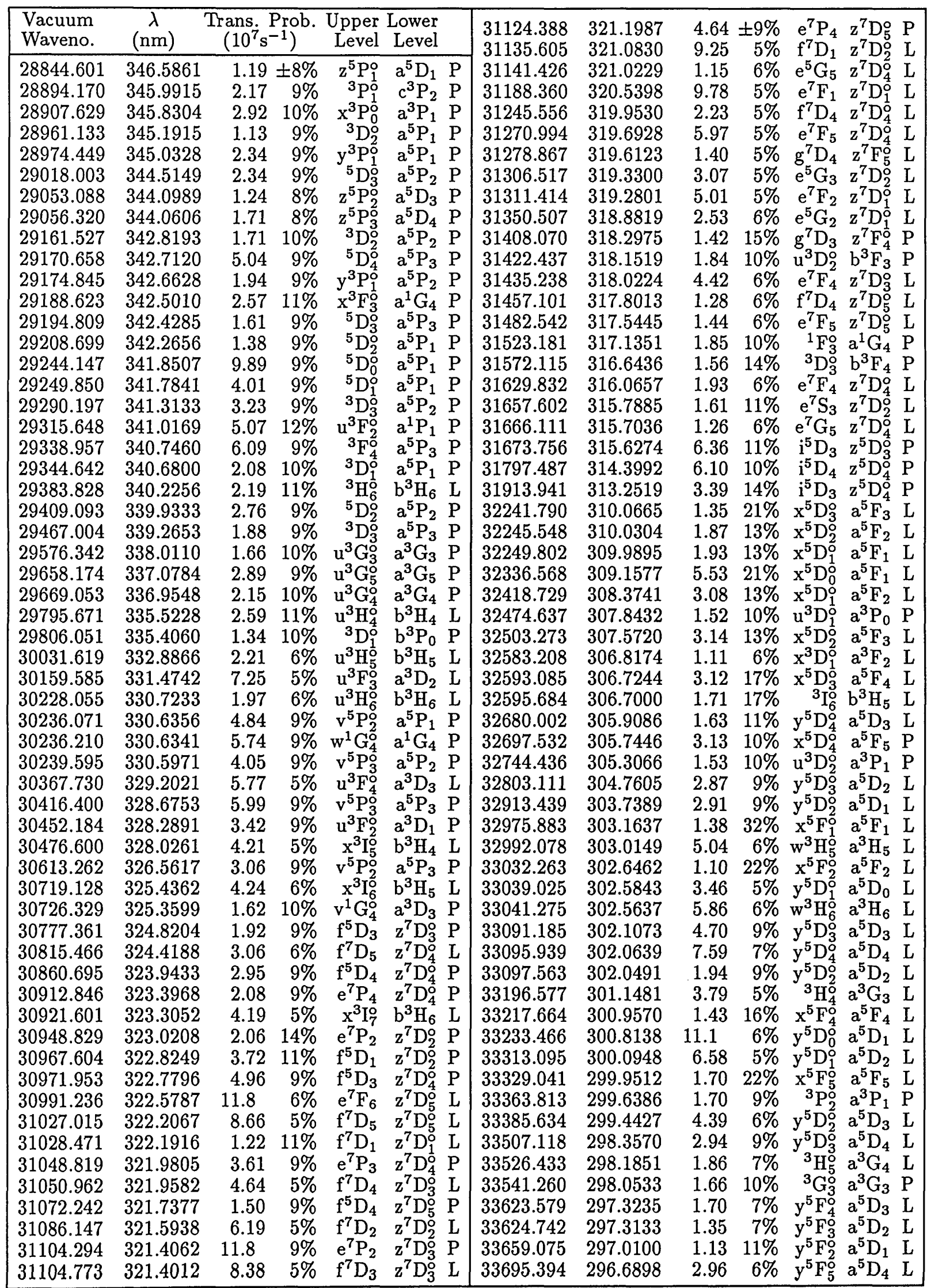


Table 2. Continued

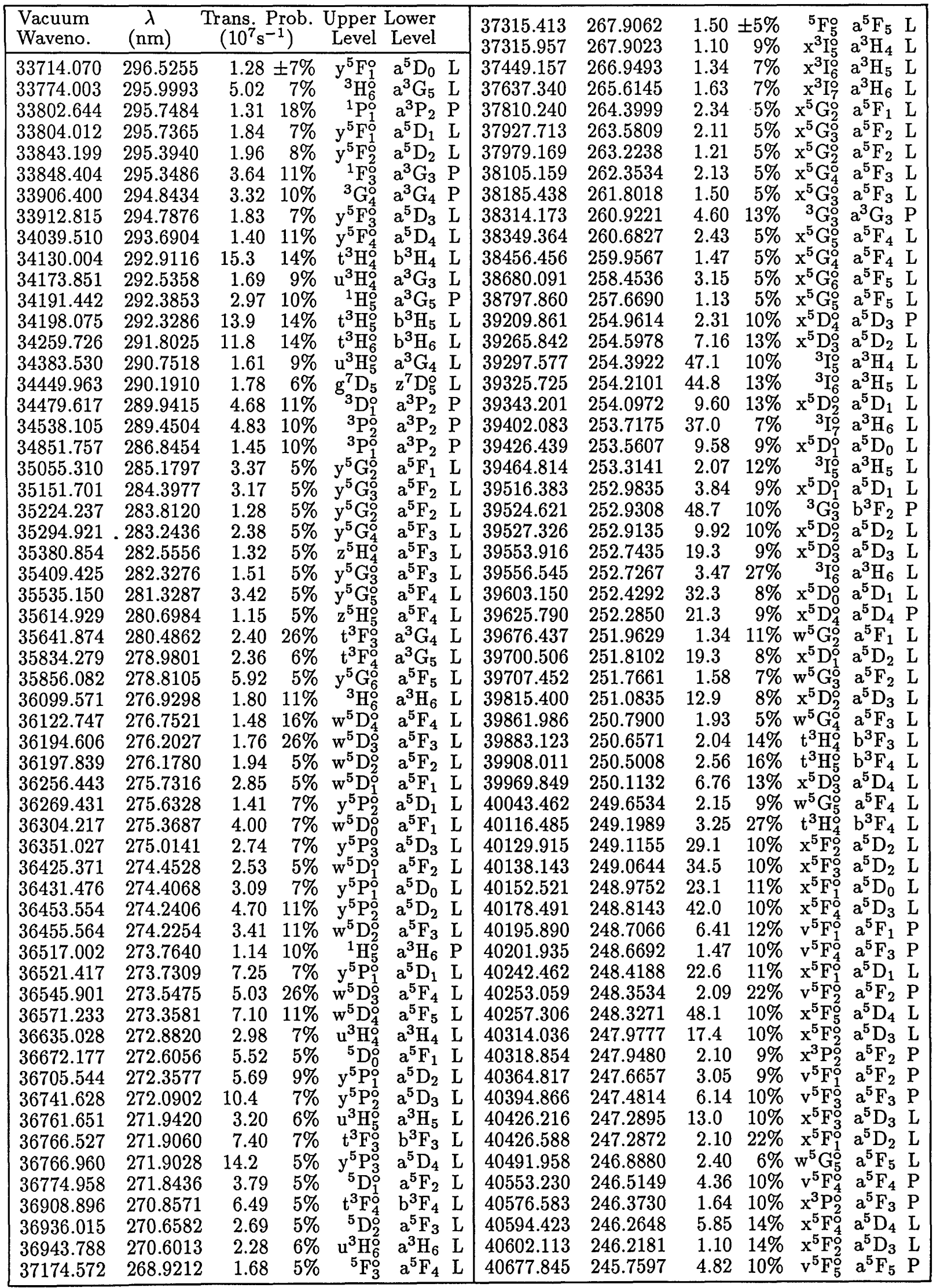




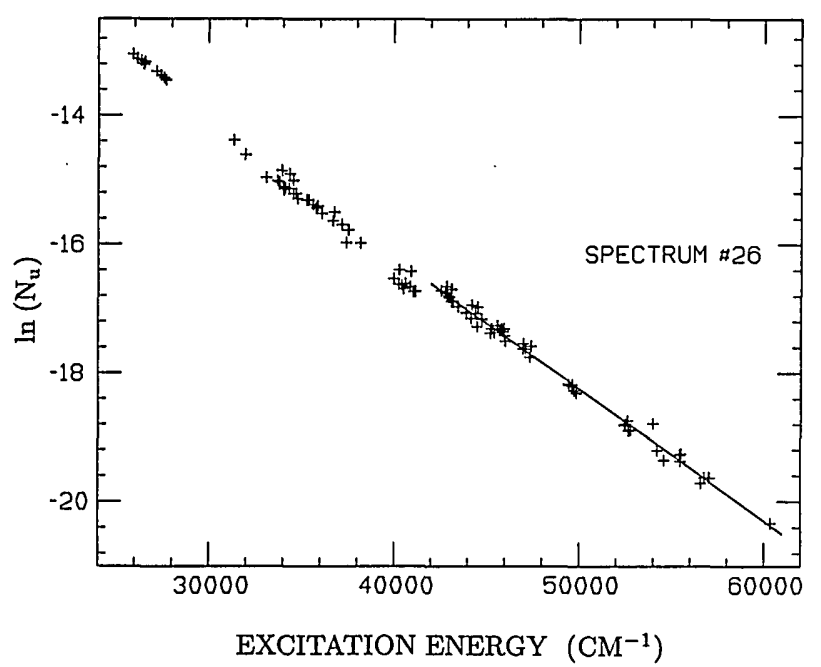

Fig. 2. Logarithm (base $e$ ) of the mean relative population per state $\bar{N}_{u}$ in an ICP spectrum containing a trace of $\mathrm{Fe}(\mathrm{CO})_{5}$ as a function of level energy. The line segment is a least-squares fit to the population per state of levels above $45000 \mathrm{~cm}^{-1}$

\section{TRANSITION PROBABILITIES FROM LEVEL POPULATIONS}

The measured intensity $I(\lambda)$ (in photons per second) of any line of known transition probability $A(\lambda)$ is related to the population $N_{u}$ per state of upper level $u$ by

$$
I(\lambda)=N_{u} g A(\lambda),
$$

where $g$ is the statistical weight of level $u$. In this section we use this relation in two ways. First, we find the relative population of excited levels in the ICP source by using the transition probabilities measured in Section 3. Then we interpolate between levels of known population to find the population $N_{u^{\prime}}$ per state of new levels of unknown lifetime. Second, we use Eq. (2) to convert the intensity of lines from level $u^{\prime}$ into transition probabilities.

In an earlier study of Mo we found that the relative population per state of excited Mo I levels in the ICP source approximated an exponential dependence on excitation energy, as if the source were in thermal equilibrium. The Fe I populations per state of excited levels do not display such regular and easily understood behavior. It may be that $\mathrm{Fe}$ and Mo behave differently in the ICP source; a more likely explanation is that the extensive level information for $\mathrm{Fe}$ reveals irregular behavior that could not be seen with the sparse Mo population data.

When several emission lines from a level have been measured, we find a mean value of $\bar{N}_{u}=\Sigma_{l} I_{u l} / g \Sigma_{l} A_{u l}$, summed over all the emission transitions from level $u$ seen in a IPC spectrum. This mean value $\bar{N}_{u}$ is shown in Fig. 2 for a broad-range spectrum (number 26-7/24/85) of an ICP source operated at relatively high power to bring up lines from high levels. The vertical scale is arbitrary: only relative populations are measured.

The population distribution in Fig. 2 shows a small upward concavity, as do all the Fe I ICP spectra that we have examined. A closer examination of individual levels shows further systematic displacements from linearity that can be seen more readily in Fig. 3, where we plot the deviation of experimental values of $\ln \left(N_{u}\right)$ from the straight line segment that best fits a limited region of ex- citation energy. The horizontal line segment shown at the top of Fig. 3 for spectrum 26 is the same line shown in Fig. 2. Levels with the shortest lifetimes (e.g., the $x^{5} D$ and $x^{5} F$ levels near $42000 \mathrm{~cm}^{-1}$ ) tend to lie lower than longer-lived levels at nearly the same excitation energy. Likewise, levels of unusually long lifetime tend to have higher populations. This dependence of population on lifetime is similar to but much smaller than that observed in the hollow-cathode source. Fortunately the deviations from a simple exponential distribution are small, and we are able to interpolate between the measured populations to estimate the populations of levels that have not been measured.

Spectrum 26 was taken with high source power, and many of the stronger lines from the lower energy levels are self-absorbed. It is advantageous to use spectra recorded at different source power levels to measure the relative population of levels in different excitation energy ranges. We use spectrum 26 only for levels with energies above $42000 \mathrm{~cm}^{-1}$, for which self-absorption is not seen on s this spectrum. The populations per state fit a straight line with a rms deviation of $9 \%$ (see Fig. 3). For spectrum 30-7/25/85, used for levels between 24000 and $42000 \mathrm{~cm}^{-1}$, the experimental populations per state fit a straight line within $8 \%$. For spectrum $12-7 / 31 / 85$, the rms deviation is $8 \%$. Filters limited spectrum 12 to the wavenumber range $18000-25000 \mathrm{~cm}^{-1}$ in order to reduce the background noise so that the weak lines from the three lowest septet terms could be measured. Lifetimes of the septet levels are too long $\left(\sim 10^{-4} \mathrm{~s}\right)$ to be measured by the methods of Section 2. The $g f$ values of Blackwell et al. ${ }^{2}$ were used to evaluate the population of the four septet levels represented by open circles in Fig. 3.

From the linear least-squares fit to the experimental points shown in Fig. 3 one can estimate the relative population $N_{u^{\prime}}$ per state of a new level $u^{\prime}$ of unknown lifetime. For at least one line $\lambda$ (selected for low noise background and a good fit to the Voigt line profile) emitted from level $u^{\prime}$, we measured $I(\lambda)$ on the ICP spectrum and calculated the transition probability $A(\lambda)=I(\lambda) / g N_{u^{\prime}}$, with fractional

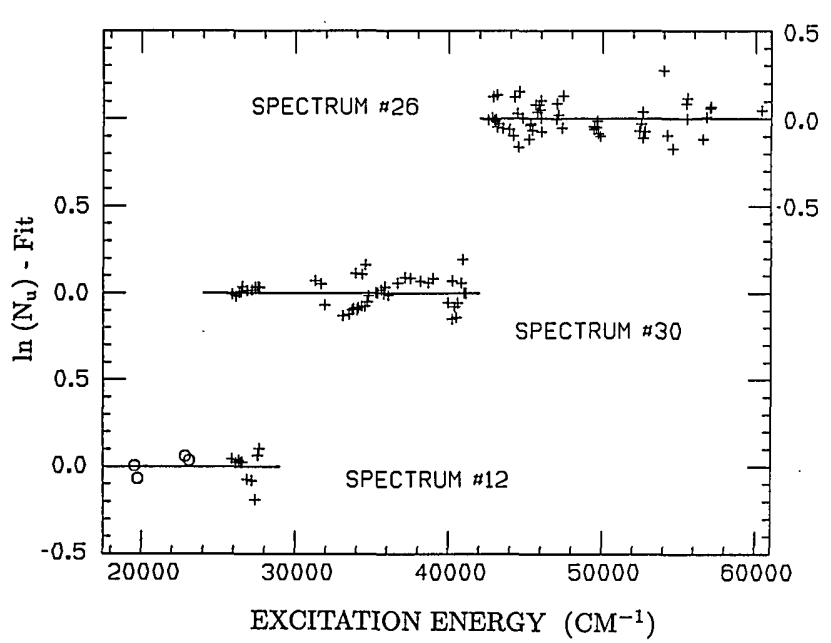

Fig. 3. Difference between $\ln (\bar{N})$ and the least-squares linear fit as a function of level energy, shown here as a horizontal line. The line segment shown for spectrum 26 is the same line as that drawn in Fig. 2; it represents a temperature of $7023 \mathrm{~K}$. Populations per state of the levels represented by open circles were evaluated with $g f$ values of Blackwell et al. ${ }^{2}$ 


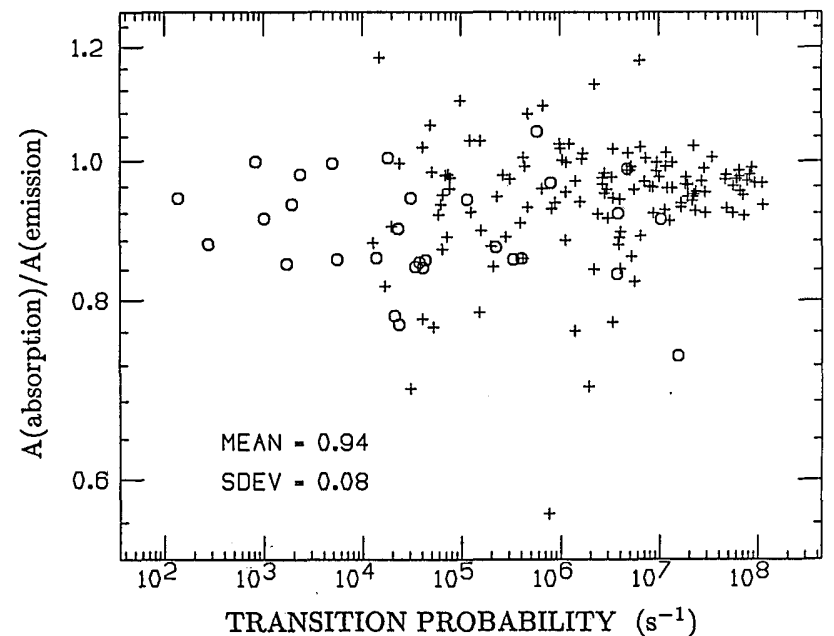

Fig. 4. Ratio of the Oxford transition probability measured in absorption to our value measured in emission for 163 ines. Pluses represent measurements by the lifetime method; circles represent measurements by interpolated level population.

uncertainty $\Delta A / A=\left[(\Delta I / I)^{2}+\left(\Delta N_{u^{\prime}} / N_{u^{\prime}}\right)^{2}\right]^{1 / 2} \cdot N_{u^{\prime}}$ is read from the linear fit shown in Fig. 3 , and for $\Delta N_{u^{\prime}} / N_{u^{\prime}}$ we use the rms deviation from the linear fit to the experimental points (i.e., $9 \%$ for spectrum 26).

Additional transition probabilities $A\left(\lambda^{\prime}\right)$ were found from line-intensity ratios $I\left(\lambda^{\prime}\right) / I(\lambda)$ of other lines $\lambda^{\prime}$ from level $u^{\prime}: \quad A\left(\lambda^{\prime}\right)=A(\lambda)\left[I\left(\lambda^{\prime}\right) / I(\lambda)\right]$ with fractional uncertainty $\Delta A^{\prime} / A^{\prime}=\left[(\Delta A / A)^{2}+\left(\Delta I^{\prime} / I^{\prime}\right)^{2}+(\Delta I / I)^{2}\right]^{1 / 2}$. Note that complete branching fractions, required when $A$ values are found from the level lifetime, are not needed; branching ratios $I\left(\lambda^{\prime}\right) / I(\lambda)$ are sufficient, and they can be measured on any spectrum. Some of the 640 transition probabilities from 104 levels measured by the population method, identified with the postscript $P$, appear in Table 2.

\section{RESULTS AND COMPARISON WITH OTHER VALUES}

Publication in this journal of all 1814 transition probabilities produced in this experiment is not feasible. In Table 2 we list values for the 478 strongest transitions that we measured. Those who need our complete results will almost certainly prefer to have them in machine-readable form. The complete list in the format of Table 2 may be obtained by BITNET request to WNW@CALTECH or by sending a 5.25 in. diskette (double sided, double density) in a reusable shipping container to $\mathrm{W}$. Whaling. Include a mailing label and specify the density $(360 \mathrm{~K}, 1.2 \mathrm{M})$ that should be used in writing the diskette, readable on an IBM or compatible microcomputer. Eventually our complete results will be deposited with the NIST Atomic Transition Probability Data Center.

We compare our transition probabilities first with the absorption oscillator strengths measured by Blackwell and his Oxford co-workers, ${ }^{2}$ widely recognized to be the most precise values available, to justify our assumption concerning the level populations in the ICP source and to confirm the reliability of our uncertainty estimates. In Fig. 4 we plot the ratio of the Oxford transition probability (measured in absorption) to our emission value for 163 lines that are common to both experiments. For 133 lines measured by the lifetime method (represented by pluses in the figure), the mean value of the ratio $A_{\mathrm{abs}} / A_{\text {emis }}$ is $\mathbf{0 . 9 5}$ with a standard deviation for the sample of 0.08 . For 30 lines measured by interpolation of level populations in the ICP source (the circles of Fig. 4), the corresponding ratio is $0.90 \pm 0.08$. We find no significant difference between the results of the two different methods. The $8 \%$ spread in the ratio $A_{\text {abs }} / A_{\text {emis }}$ is consistent with the fractional uncertainties (in parentheses) assigned to the transition probabilities in Table 2. That this spread is no larger for the values obtained by the population method confirms our confidence in the ICP source as a useful tool for measuring transition probabilities, and the magnitude of the spread validates our uncertainty assignments.

To test the suggestion ${ }^{21}$ of a temperature error in the Oxford measurements, we plot in Fig. 5 the ratio $A_{\text {abs }} / A_{\text {emis }}$ as a function of the energy of the lower level in the transition. We use only stronger lines with minimum uncertainty for this test; the 66 points in Fig. 5 are all the transitions measured at Oxford and by us to which we assign an uncertainty $\leq 6 \%$. As first noted by Kock et al., ${ }^{21}$ the ratio appears to be lower (by $\sim 5 \%$ ) for transitions involving levels near $20000 \mathrm{~cm}^{-1}$ than it is for transitions from lower levels. However, we do not observe the exponential variation with excitation energy that is characteristic of a temperature error in the absorption furnace. Within our experimental uncertainty (5-6\% for the points plotted in Fig. 5) the ratio is independent of excitation energy for levels below $14000 \mathrm{~cm}^{-1}$.

The recent critical compilation by the NIST Atomic Transition Probability Data Center ${ }^{3}$ contains 728 of the transitions that we have measured. These include the 163 Oxford $g f$ values, to which we have already made comparison and therefore exclude from the following discussion, plus an additional 565 values taken from many sources; many of the latter values have been adjusted or renormalized by NIST compilers to conform to the most modern and accurate standards. On average our values agree quite well with these 565 NIST values: The mean value of $\ln \left(A_{\mathrm{NIST}} / A_{\text {emis }}\right)=0.02 \pm 0.35$. The $\pm 42 \%$ scatter is reasonable, since the NIST compilation includes values with an uncertainty within $\pm 50 \%$.

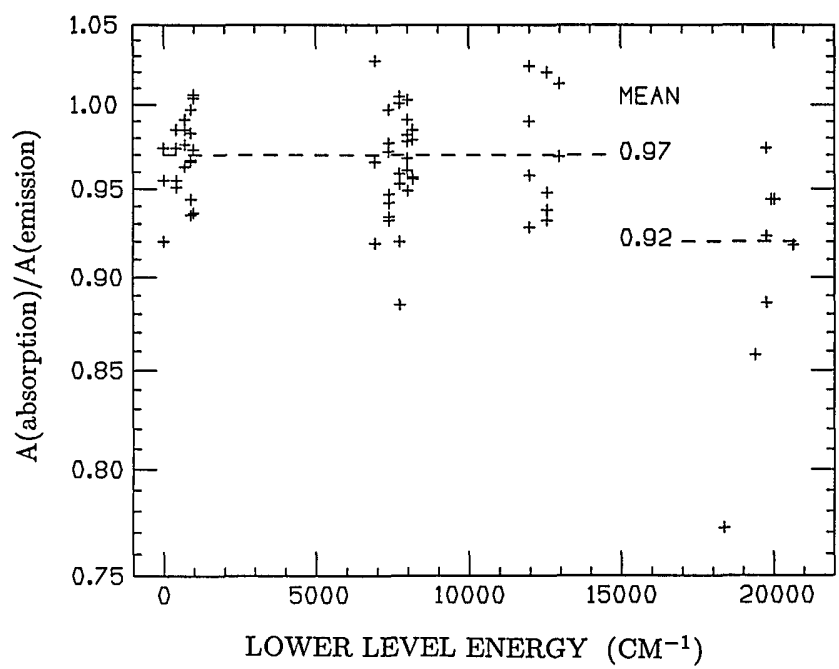

Fig. 5. Ratios from Fig. 4 plotted as a function of lower level energy. Only the strongest 66 lines with uncertainty in $A_{\text {emis }} \leq$ $6 \%$ are shown. The low point at $18378 \mathrm{~cm}^{-1}$ was ignored for computation of the mean value shown. 


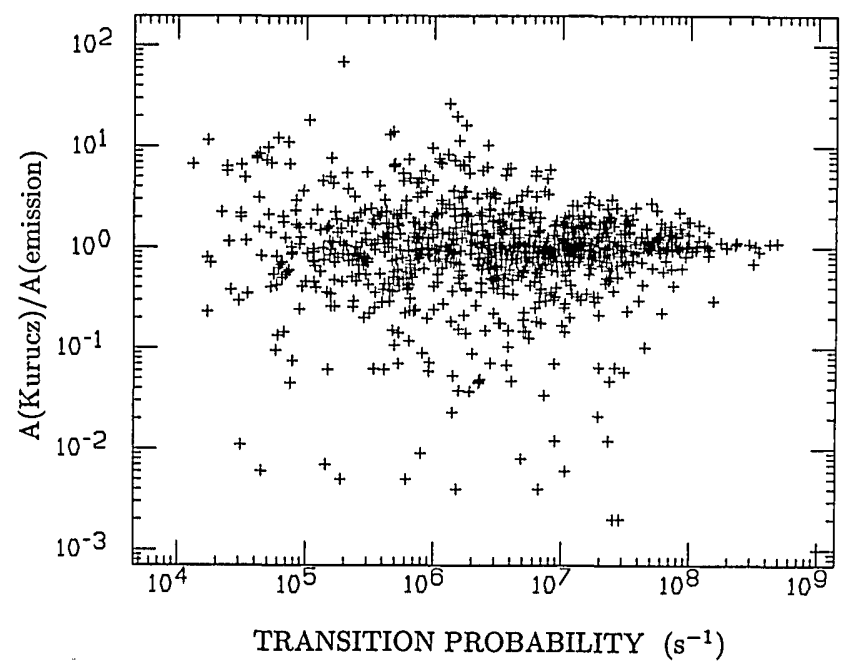

Fig. 6. Ratio of semiempirical transition probabilities computed by Kurucz ${ }^{4}$ to our experimental values. Mean of 1117 values is 0.93 . Two thirds of the theoretical values lie within a factor of 3 of the experimental values.

The recent publication by Kock et al. ${ }^{21}$ of $122 \mathrm{Fe}$ I transition probabilities appeared too late to be included in the NIST compilation. We have measured 110 of the transitions measured by Kock et al. The mean value of $\ln \left(A_{\text {Kock }} / A_{\text {emis }}\right)$ is $0.02 \pm 0.25$.

We made extensive use of the Kurucz semiempirical transition probabilities ${ }^{4}$ in our branching-fraction measurements, and it is of interest to find out how reliable his computed values are by comparing them with experimental values. Figure 6 shows the ratio $A_{\text {Kurucz }} / A_{\text {emis }}$ for 1117 values measured by the lifetime method; a plot of values measured from populations looks much the same. The mean value of the natural logarithm of the ratio is $-0.07 \pm$ 1.07; two thirds of the theoretical values lie within a factor of 3 of the experimental value. Since Kurucz has calculated essentially every transition between all known energy levels in $\mathrm{Fe} \mathrm{I}$, his tables are quite useful when precision of this order is adequate. We used his values in deciding when transitions outside the range of our spectra contribute negligibly to the total transition strength and also when transitions with spin change $\Delta S>1$ may make a significant contribution.

\section{Fe I LEVEL ENERGIES}

Identification of lines in our FTS spectrum is based on near coincidence (within $\pm 0.01 \mathrm{~cm}^{-1}$ ) between the observed vacuum wave number and a predicted transition energy. The predicted line list used for this identification contains all transitions between known $\mathrm{Fe}$ I levels that satisfy the conditions parity change, $\delta J=0, \pm 1$, and $\delta S=0, \pm 1$.

Line identification on the basis of wavelength alone sets severe requirements for the level energies used in preparing the predicted line list. In addition to the obvious need for precise energies and correct $J$ values (and if possible correct $L$ and $S$ values as well), there is another requirement that we have come to appreciate as we compare spectra from different sources: The level energies must be those appropriate to the spectral source used to produce the spectrum. This requirement can be satisfied only by determining the level energies from the spectrum itself, i.e., from the observed transition energies. To find level energies that meet these requirements, we carried out the following iterative process.

Step 1. Starting with the energy levels in the $1985 \mathrm{AEL},{ }^{5}$ we prepared the predicted line list, as described above, containing 12,224 lines between 8000 and $45000 \mathrm{~cm}^{-1}$.

Step 2. For a selected hollow-cathode spectrum (number $6-2 / 12 / 83$ ), covering the range $8000-45000 \mathrm{~cm}^{-1}$, we measured all lines with a signal-to-noise ratio greater than 3 , using the Kitt Peak DECOMP program to fit a Voigt profile to the observed line in order to find the line-center wave number. The observed line list contains 6280 lines, including $\mathrm{Fe}$ II, $\mathrm{Ar}$, and $\mathrm{Ne}$ as well as $\mathrm{Fe}$.

Step 3. A computer search for predicted lines within $0.01 \mathrm{~cm}^{-1}$ of an observed line produced an identified line list of $2144 \mathrm{Fe}$ I lines. In spite of the small search window, our search program assigned two different classifications to $\sim 100$ lines; i.e., two predicted lines fell within $\pm 0.01 \mathrm{~cm}^{-1}$ of the observed line. The choice between the two alternative assignments could usually be made on the basis of the semiempirical $g f$ values computed by Kurucz ${ }^{4}$ for the two transitions. If no choice was possible, both lines were deleted. The level energies are greatly overdetermined (2144 transitions to determine 442 levels), so that a few uncertain lines could be dropped with little loss.

Step 4. The observed vacuum wave numbers in the identified line list give precise energy differences $\Delta E_{i j}=$ $E_{i}-E_{j}$ between the level energies appropriate to our source, and the $\Delta E_{i j}$ 's can be used to find the set of most probable level energies $\left\{E_{i}\right\}$ by the least-squares method. We used the CLEVEL least-squares code of Palmer and Engleman $^{22}$ to solve for the energies. Their solution assigns to each observed transition $\Delta E_{i j} \pm \delta \Delta E_{i j}$ a weight proportional to $\left(\delta \Delta E_{i j}\right)^{-2}$, so that a reliable estimate of the experimental uncertainty $\delta \Delta E_{i j}$ becomes an important part of the solution.

Following the analysis of Brault, ${ }^{23}$ we take $\delta \Delta E_{i j}=$ $(1 / 2) \mathrm{FWHM} /\left(S / N_{t}\right)$, where FWHM is the full width at half-maximum of the line of peak amplitude $S$ and $N$ is the total noise amplitude. The total noise amplitude $N_{t}$ has two components: In addition to the usual rms background noise $N_{c}$ that one sees between lines and measures by moving several linewidths away from the line center a FTS spectrum contains another noise component $N_{S}$ that is produced by variation in source brightness during the observation. $N_{S}$ is proportional to the peak amplitude: $N_{S}=\kappa S$. Unlike $N_{c}$, which is nearly independent of wave number, $N_{S}$ is present only under the line itself and can be seen and measured only after the contribution of the line from the observed spectrum is subtracted. The total noise amplitude is given by $N_{t}=\left(N_{c}^{2}+N_{S}^{2}\right)^{1 / 2}$. The constant $\kappa$ is sufficiently small (0.006 for spectrum $6-3 / 12 / 83)$ that the $N_{S}$ is negligible except for the strongest line, where it limits $S / N_{t}$ to a maximum value of $\sim 170$.

We tested our uncertainty estimate by comparing our wave numbers with those of Learner and Thorne, ${ }^{24}$ who carefully measured 312 stronger $\mathrm{Fe}$ I lines as transfer wave-number standards. The average difference between our wave numbers and theirs is consistent with the uncertainty that we estimate by the method described above. 
In addition to the statistical uncertainty that depends on linewidth and signal-to-noise ratio there is an uncertainty associated with the alignment factor. If the light beam entering the FTS from the source is not exactly parallel to the He-Ne laser beam that is used to monitor the mirror displacement, one must multiply the wave-number scale of the FTS by a constant factor to correct for the misalignment. We found the alignment factor $F \pm \delta F$ (0.999 $999483 \pm 63$ for spectrum 6-3/12/83) by comparing the wave numbers of $\mathrm{Ar}$ II lines measured in our $\mathrm{Fe}+$ $\mathrm{Ne}+\mathrm{Ar}$ spectrum with the values of Norlén. ${ }^{25}$ For this comparison we used the 28 standard Ar II lines recommended by Learner and Thorne ${ }^{24}$ as relatively insensitive to pressure shift.

The uncertainty $\pm \delta F$ in the alignment factor deserves some mention because it makes the largest contribution to the uncertainty in the transition energy, at least for the stronger lines that dominate the least-squares solution because of their greater weight. Although we treat $F$ as a constant, it could depend on the energy of the upper level, because the pressure in Nolen's source was lower than that in ours; we note the effect of source pressure below in this section. Or $F$ could vary with wave number if there is a phase error in our spectrum; Learner and Thorne ${ }^{24}$ discuss the effect of FTS phase correction on wave number. Because of the possibility that $F$ is dependent on variables that we ignore, we take $\delta F$ to be the standard deviation of the sample of 28 independent measurements of $F . \quad \delta F$ is then a measure of our exposure to systematic error arising from the method we use to calibrate the FTS wave-number scale.

However, it should be noted that $\delta F$ (and indeed the correction factor $F$ itself) may be ignored in the transition energy $\Delta E_{i j} \pm \delta \Delta E_{i j}$ that is input to the least-squares solution and applied only to the results of the calculation, $E_{i}$, because the factor $F$ is common to every energy term. Along with the most probable energy values $E_{i}$, the CLEVEL code also finds the uncertainty $\delta E_{i}$ that is produced by the uncertainty in the observations. $\delta E_{i}$ is less than $0.001 \mathrm{~cm}^{-1}$ for most levels and is combined with the uncertainty arising from the alignment factor $\delta E_{F}=$ $(\delta F / F) E_{i}=\left(6.3 \times 10^{-8}\right) E_{i}$ to obtain the total uncertainty $\left[\left(\delta E_{i}\right)^{2}+\left(\delta E_{F}\right)^{2}\right]^{1 / 2}$ assigned to the level energies in Table 3.

Step 5. The level energies $E_{i}$ that were determined in this least-squares solution were then used to calculate an improved version of the predicted line list, and the sequence of steps 1-4 was repeated to yield the level energies listed in Table 3, refined values for the energy of levels listed in the AEL that satisfy our requirements. The uncertainty in the last digits of the level energy appears in parentheses after the energy value. For comparison we also list the level energies from the $1985 \mathrm{AEL}^{5}$ The level designations follow the recommendations of Brown et al. ${ }^{26}$

A few levels are included in Table 3 even though we see only a single line from the level if (1) the line is expected to be the strongest decay channel within our spectral range on the basis of Kurucz $g f$ values $^{4}$ and (2) Brown et $a l .{ }^{26}$ confirm the identification of the line in their absorption spectra.

Forty-seven levels in the AEL do not appear in Table 3. Most of the missing levels are $5 p$ levels that decay primarily by means of IR transitions outside the 8000-
$45000 \mathrm{~cm}^{-1}$ range of spectrum 6-3/12/83. We have seen these IR transitions on other spectra that were used for IR branching-fraction measurements, but, in the interest of presenting a set of level energies based on a single spectrum, in Table 3 we do not include the $5 p$-level energies that can be derived from IR transitions. The following levels were not represented on any of our spectra, even though one expects decay channels within our spectral range: $y^{1} H_{5}^{\circ}(53722.40),{ }^{5} F_{2}^{\circ}(53275.23), z^{1} D_{2}^{\circ}(49477.10)$, $r^{3} G_{3,4,5}^{\circ}\left(60364,60172,59926 \mathrm{~cm}^{-1}\right)$. These levels were not seen in the absorption spectra of Brown et al. ${ }^{26}$ and we doubt their existence.

After we identified $2144 \mathrm{Fe}$ I lines and $161 \mathrm{Fe}$ II lines in spectrum 6, many unidentified lines remained. Some of these are from the neutral and ionized $\mathrm{Ar}$ and $\mathrm{Ne}$ used in the hollow-cathode source, but there are also Fe lines from unknown $\mathrm{Fe} I$ levels. We searched for new levels by adding and subtracting the energy $\Delta E_{u}$ of unclassified transitions to our known energy levels $E_{i}$ of odd (or even) parity. The set $\left\{E_{i} \pm \Delta E_{u}\right\}_{i u}$ contains possible values for an unknown even-parity energy level involved in the transition of energy $\Delta E_{u}$. A cluster of close values in this set, where all partner levels satisfy the $\delta J$ selection rule, suggests a possible even- (or odd-) parity level. Additional tests and details of the search procedure are described in Ref. 1. The following levels that do not appear in the $1985 \mathrm{AEL}^{5}$ were identified in this way:

$E=43460.117 \mathrm{~cm}^{-1}, J=5$, odd parity; $E=$ $43442.699 \mathrm{~cm}^{-1}, J=4$, odd parity. Brown et al. ${ }^{26}$ also saw these levels in absorption and labeled them $z^{5} I_{5}^{\circ}$ and $z^{5} I_{4}^{\circ}$, respectively.

$E=49477.124 \mathrm{~cm}^{-1}, J=3$, odd parity, probably $S=0$ because strong transitions are to singlet levels. The AEL lists a level nearby at $49477.10 \mathrm{~cm}^{-1}$, but its designation $z^{1} D_{2}^{\circ}$ is wrong. We believe that this level should be labeled $3 d^{6}\left(a^{3} F\right) 4 s 4 p\left({ }^{3} P^{\circ}\right)^{1} F_{3}^{\circ}$ because a singlet $F$ level is expected in this neighborhood, and the level labeled ${ }^{1} F_{3}$ in the AEL at $49227.12 \mathrm{~cm}^{-1}$ is one of those for which we see no evidence.

$E=53852.110 \mathrm{~cm}^{-1}, J=4$, odd parity. We believe that this is the correct $J$ assignment for the level designated ${ }^{5} G_{3}^{\circ}$ in the AEL at $53852.108 \mathrm{~cm}^{-1}$.

$E=24574.650 \mathrm{~cm}^{-1}, J=4$, even parity, $a^{1} G_{4}$ in the AEL. Many emission lines to this level appear in our spectrum: 8 lines (including the strongest) are from singlet upper levels, 16 are from triplet upper levels, 9 are from quintet levels, and 1 is from a level of unknown spin. The quintet partners would lead us to classify this as a triplet level, but Johansson ${ }^{27}$ advises that the $\delta S=2$ transitions reflect spin impurity in the high odd partners. We have not seen $\delta S=2$ transitions to other levels, but a thorough search with a $\delta S=2$ predicted line list has not been made.

The level energies in Table 3 are notable in two respects: They have greater precision than any other comprehensive set now available, and they constitute a self-consistent set because all level energies were derived from a single spectrum. A transition energy $\Delta E$, obtained from the difference between level energies in Table 3 , is far more precise than either level energy alone, because the systematic uncertainty in $\Delta E$ is only $6.3 \times 10^{-8} \Delta E$. However, we em- 
Table 3. Fe I Level Energy*

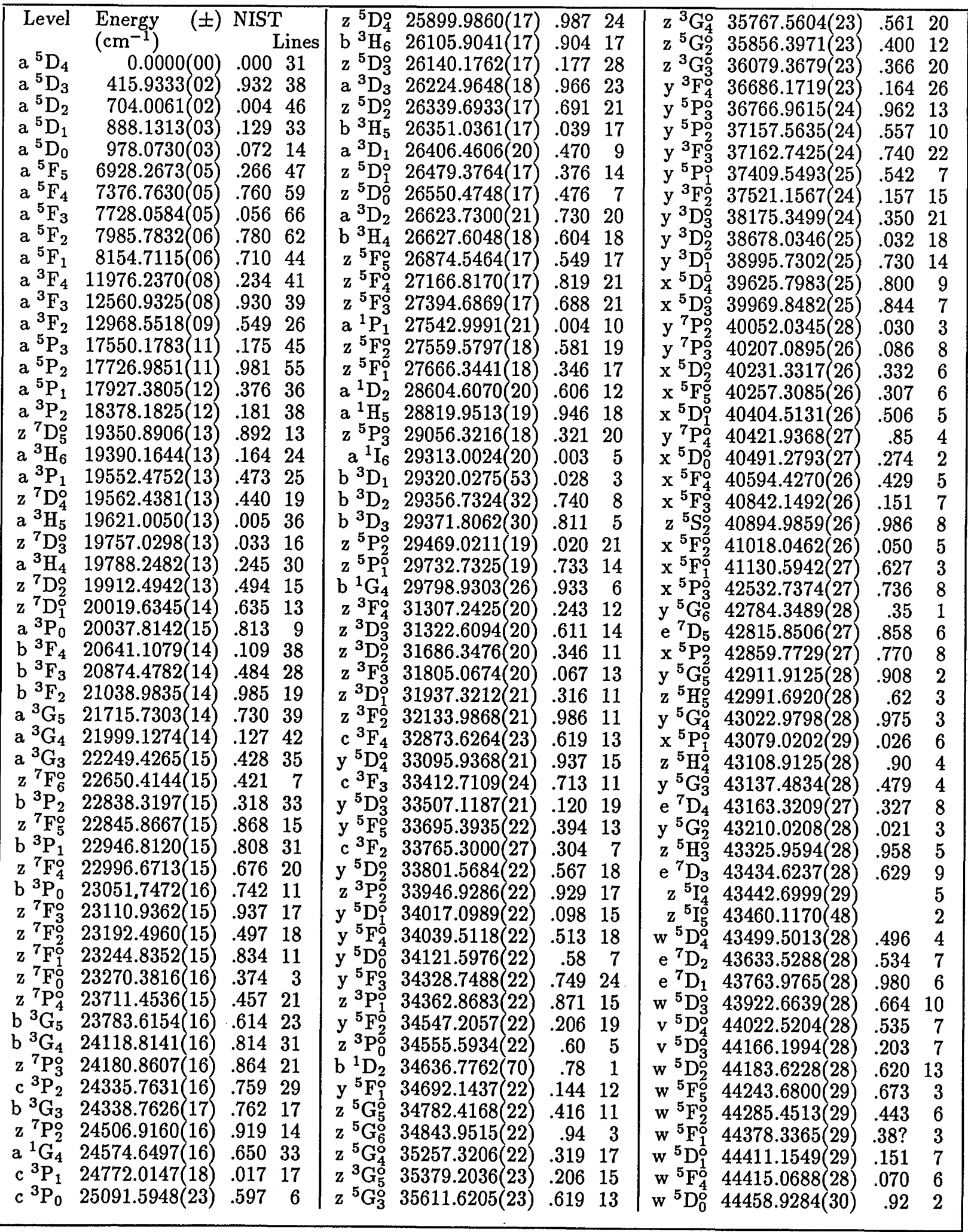


Table 3. Continued

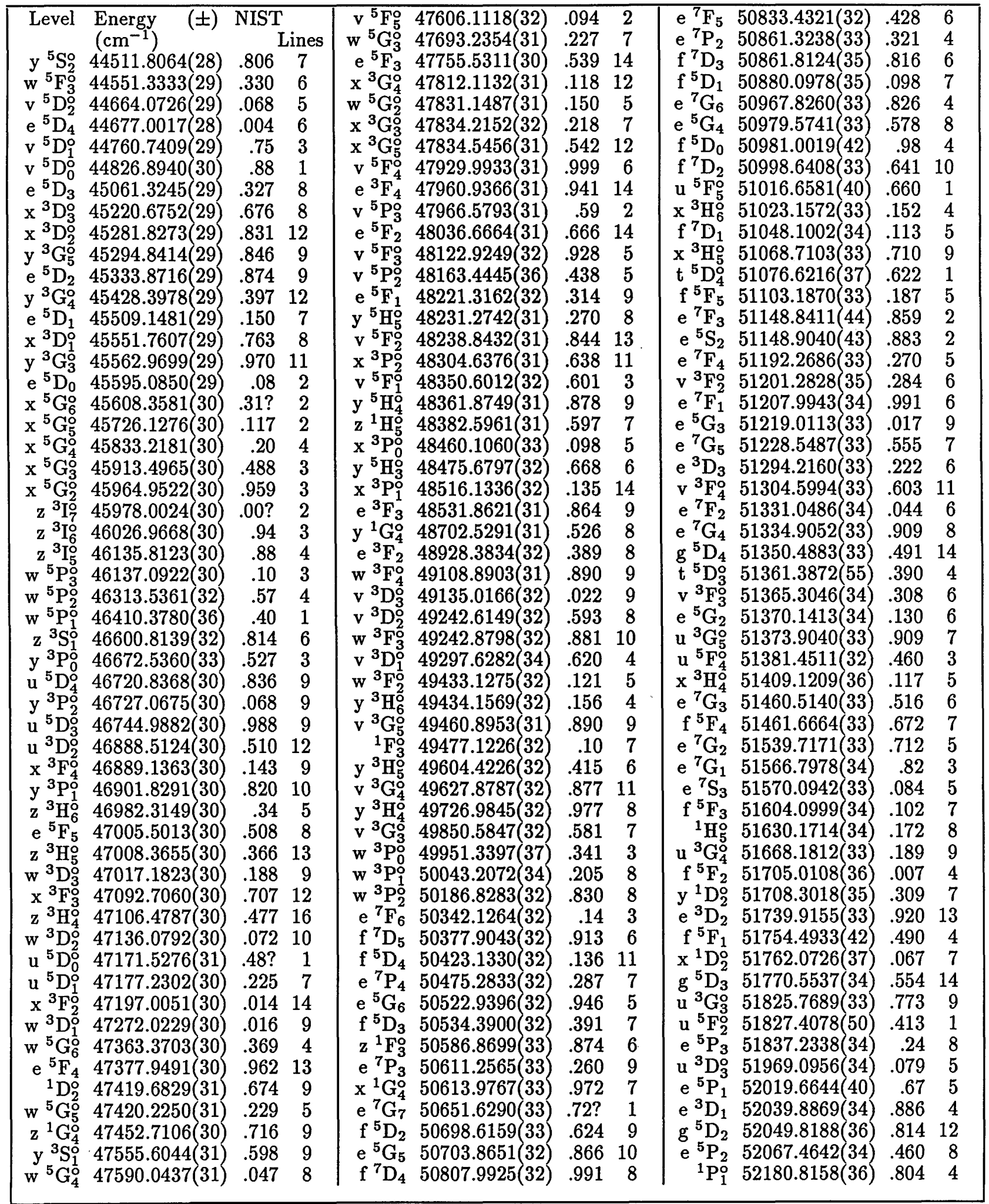


Table 3. Continued

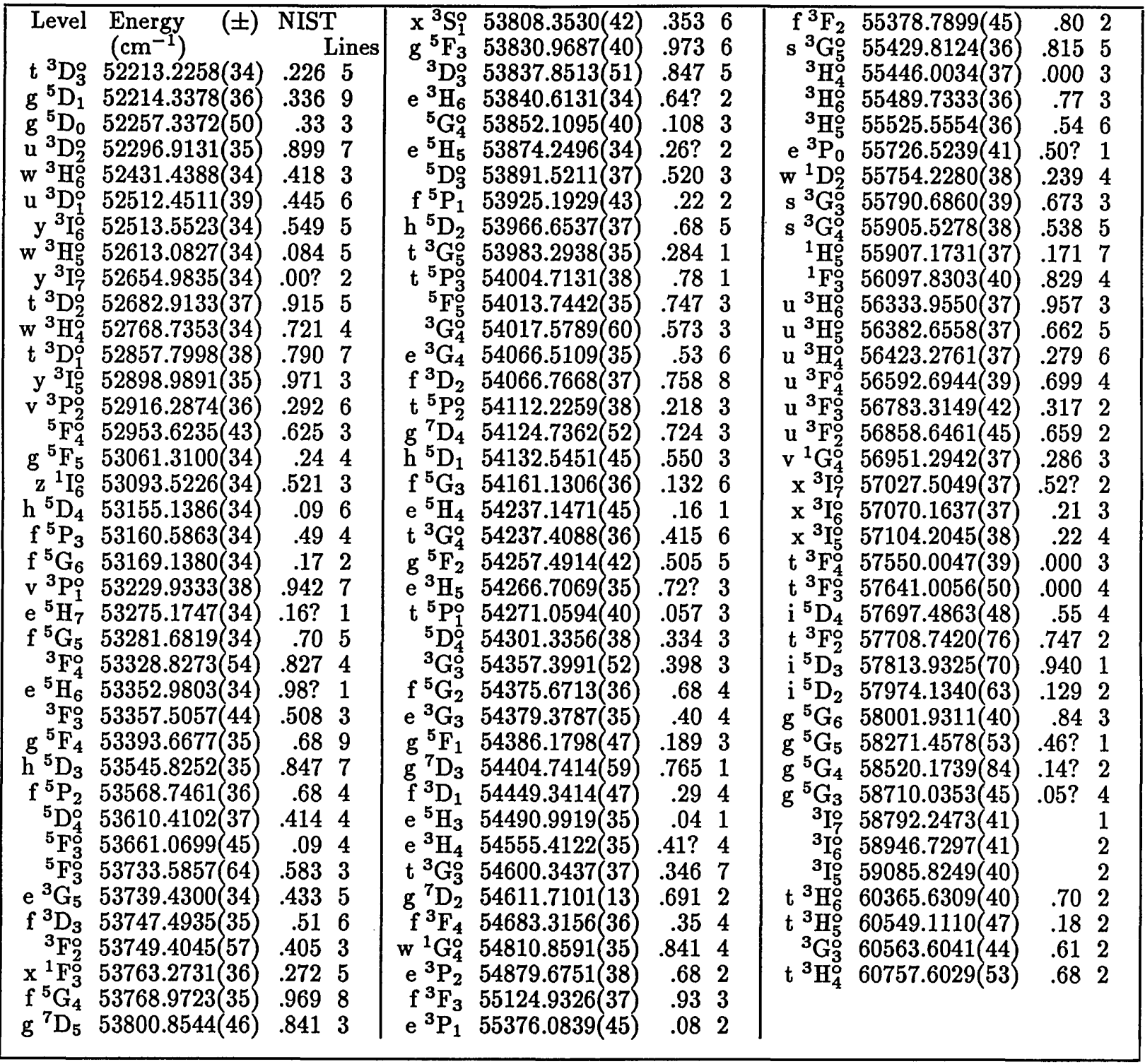

*The column headed NIST shows decimal digits of the energy given in Ref. 5. Last column shows the number of measured transitions involving the level. The uncertainty in the last digit(s) appears in parentheses.

phasize that these level energies apply to a particular hollow-cathode source $(8 \mathrm{~mm}$ in diameter by $30 \mathrm{~mm}$ long, $0.85 \mathrm{~A}$ at $250 \mathrm{~V}, 2.5$ Torr $\mathrm{Ne}+0.6$ Torr Ar). By the same method we measured level energies in the inductively coupled Ar plasma source at a pressure of 600 Torr. Fe I level energies in the ICP source are shifted by as much as $\pm 0.02 \mathrm{~cm}^{-1}$, and in both directions, from those in Table 3 .

We compared our level energies with those in the 1985 AEL of Sugar and Corliss ${ }^{5}$ and with the recent measurements of absorption spectra by Brown et al. ${ }^{26}$ The third column of Table 3 shows the decimal digits of the level energy from the AEL; for 31 levels (excluding those levels noted in the AEL by a question mark or with only one or two digits after the decimal) we differ from the AEL value by $\geq 0.010 \mathrm{~cm}^{-1}$. Our values differ from the level energies measured by Brown et al. by more than $0.02 \mathrm{~cm}^{-1}$ for six levels. We have carefully reexamined and confirmed the experimental evidence for those values that are in disagreement.

\section{ACKNOWLEDGMENTS}

This research was supported in part by National Science Foundation grants AST 87-13904 and AST 88-21051. W. Whaling was a guest observer at the National Solar Observatory (Kitt Peak) during this research. The ICP used in this work was first brought to the National Solar Observatory by Lynda M. Faires of Los Alamos National Laboratory to investigate the potential of an ICP FTS for analytical chemistry, and we are grateful for her assistance in the operation of the source for the acquisition of the present data. We are also grateful to Rolf Engleman, formerly of that laboratory, who has been responsible for a number of improvements in our use of both the hollow- 
cathode source and the ICP source (especially with respect to the use of carbonyl and halide vapors of several metals). M. J. Seaton of University College, London, kindly provided unpublished He $g f$ values that were used to calibrate the IR response of the FTS. We are indebted to R. L. Kurucz of the Center for Astrophysics for generously supplying millions of semiempirical $g f$ values. Finally, we thank S. E. Johansson for valued criticism of our Fe I level energies.

The National Solar Observatory, National Optical Astronomy Observatory, is operated by the Association of Universities for Research in Astronomy, Inc., under a cooperative agreement with the National Science Foundation.

\section{REFERENCES}

1. W. Whaling and J. W. Brault, "Comprehensive transition probabilities in Mo I," Phys. Scr. 38, 707-718 (1988).

2. D. E. Blackwell, A. D. Petford, and G. J. Simmons, "Measurements of relative oscillator strengths for Fe I," Mon. Not. R. Astron. Soc. 201, 595-602 (1982), and references therein.

3. J. R. Fuhr, G. A. Martin, and W. L. Wiese, "Atomic transition probabilities: Fe through Ni," J. Phys. Chem. Ref. Data 17, Suppl. 4 (1988).

4. R. L. Kurucz, "Semi-empirical calculation of gf-values for the iron group," Trans. Int. Astron. Union B 20, 168-172 (1990); magnetic tape data.

5. J. Sugar and C. Corliss, "Atomic energy levels of the ironperiod elements: K through Ni," J. Phys. Chem. Ref. Data 14, Suppl. 2 (1985).

6. J. E. Lawler in Lasers, Spectroscopy, and New Ideas: A Tribute to Arthur L. Schawlow, W. M. Yen and M. D. Levenson, eds., Vol. 54 of the Springer Series in Optical Sciences (Springer, New York, 1988), p. 125-140.

7. D. W. Duquette and J. E. Lawler, "Radiative lifetimes in NbI," Phys. Rev. A 26, 330-334 (1982).

8. S. Salih, J. E. Lawler, and W. Whaling, "Lifetimes, branching ratios, and transition probabilities in Co II," Phys. Rev. A 31, 744-749 (1985).

9. G. C. Marsden, E. A. Den Hartog, J. E. Lawler, J. T. Dakin, and V. D. Roberts, "Radiative lifetimes of even- and odd-parity levels in Sc I and Sc In,"J. Opt. Soc. Am. B 5, 606-613 (1988).

10. H. Figger, K. Siomos, and H. Walther, "Lifetime measurements in the Fe I spectrum using tunable dye laser excitation," Z. Phys. 270, 371-376 (1974).
11. J. Marek, J. Richter, and H. J. Stahnke, "Radiatives lifetimes of some Fe I levels," Phys. Scr. 19, 325-327 (1979).

12. P. Hannaford and R. M. Lowe, "Determination of atomic lifetimes using pulsed laser excitation of sputtered metal vapours," J. Phys. B 14, L5-L9 (1981)

13. H. Figger, J. Heldt, K. Siomos, and H. Walther, "Lifetime measurements in the Co I and Fe I spectra using tunable dye laser excitation," Astron. Astrophys. 43, 389-394 (1975).

14. J. Carlsson, L. Sturesson, and S. Svanberg, "Accurate timeresolved laser spectroscopy on sputtered metal atoms," Z. Phys. D 11, 287-293 (1989).

15. K. Siomos, H. Figger, and H. Walther, "Lifetime measurements in the Fe I spectrum using stepwise excitation by dye lasers," Z. Phys. A 272, 355-358 (1975).

16. J. W. Brault, "Rapid-scan high-resolution Fourier spectrometer for the visible," J. Opt. Soc. Am. 66, 1081 (1976).

17. B. A. Palmer, M. V. Phillips, and R. Engleman, "The infrared emission spectrum of U and Th," Proc. Soc. Photo-Opt. Instrum. Eng. 380, 415-435 (1983).

18. W. L. Wiese, J. W. Brault, K. Danzmann, V. Helbig, and M. Kock, "Unified set of atomic transition probabilities for neutral argon," Phys. Rev. A 39, 2461-2471 (1989).

19. J. A. Fernley, K. T. Taylor, and M. J. Seaton, "Atomic data for opacity calculations," J. Phys. B 20, 6457-6476 (1987).

20. L. M. Faires, B. A. Palmer, and J. W. Brault, "Line width and line shape analysis in the ICP by high-resolution FT spectrometry," Spectrochim. Acta 40B, 135-145 (1985).

21. M. Kock, S. Kroll, and S. Schnehage, "Fe I oscillator strengths," Phys. Scri. T8, 84-87 (1984).

22. B. A. Palmer and R. Engleman, "A new program for the least squares calculation of atomic energy levels," Report LA-9710 (Los Alamos National Laboratory, Los Alamos, N. Mex., 1983).

23. J. W. Brault, in R. S. Booth, J. W. Brault, and A. Labeyrie, High Resolution in Astronomy (Geneva Observatory, Geneva, 1985).

24. R. C. M. Learner and A. P. Thorne, "Wavelength calibration of Fourier transform emission spectra with applications to Fe I," J. Opt. Soc. Am. B 5, 2045-2059 (1988).

25. G. Norlén, "Wavelengths and energy levels of Ar I and Ar II based on new interferometric measurements in the region 3400-9800 A," Phys. Scr. 8, 249-268 (1973).

26. C. M. Brown, M. L. Ginter, S. Johansson, and S. G. Tilford, "Absorption spectra of $\mathrm{Fe} I$ in the 1550-3215- $\AA$ region," J. Opt. Soc. Am. B 5, 2125-2158 (1988).

27. S. E. Johansson, Department of Physics, University of Lund, Sölvegatan 14, S223 62 Lund, Sweden (personal communication). 